Citation: Vieira A.S., Beal, C.D. and Stewart, R.A. (2014) Residential water heaters in Brisbane, Australia: thinking beyond technology selection to enhance energy efficiency and level of service. Energy \& Buildings, 82, 222-236.

http://dx.doi.org/10.1016/j.enbuild.2014.07.007

\title{
Residential water heaters in Brisbane, Australia: thinking beyond technology selection to enhance energy efficiency and level of service
}

\section{Highlights:}

- Controlled electricity tariff enhanced the performance of water heating systems;

- $\quad$ Night off-peak electricity tariff reduced the performance of water heating systems;

- $\quad$ Solar water heaters are likely to be more resilient to Legionella sp. growth;

- Water efficient washing machines may promote energy inefficiency.

\author{
Abel S. Vieira ${ }^{\mathrm{a}}$, Cara D. Beal ${ }^{\mathrm{b}}$ and Rodney A. Stewart ${ }^{\mathrm{a}}$ \\ ${ }^{\text {a }}$ School of Engineering, Griffith University, Gold Coast Campus, Queensland 4222, Australia; ${ }^{\text {b }}$ Smart Water \\ Research Centre and School of Engineering, Griffith University, Gold Coast Campus, Queensland 4222, \\ Australia
}

\section{Corresponding author:}

Associate Professor Rodney Stewart

Griffith School of Engineering, Gold Coast Campus, Griffith University, Parklands Drive, Southport, QLD 4222 Australia;

Phone: $\quad+61755528778$

Email: r.stewart@griffith.edu.au

\begin{abstract}
A holistic approach to residential water heating systems specification is required to provide optimal energy efficiency. The objective of this study is to analyse the performance of residential water heating systems for the city of Brisbane in Australia, for different combinations of heating system technologies (solar, heat pump, electric), storage tank sizes (125 l, 250 l, 325 l), time-distribution of energy in accordance to the tariff selection (all-day, controlled, night off-peak) and washing machine water heating source (internal and external). Performance assessments considered the influence of 54 different water heating system configurations on the electricity grid (i.e. power peaks, time-distribution of energy according to electricity tariffs, and energy intensity), as well as their level of service (i.e. compliance rates with recommended hot water temperatures). Empirical water end use data from 27 households was utilised to model the performance of water heating systems. The study demonstrated that beyond merely specifying the type of technology (e.g. solar hot water), other key criteria such as hot water demand, hot water tank size and water tariff selection should also be considered in order to systematically optimise the energy and service performance of hot water systems in residential buildings.
\end{abstract}

Keywords: residential buildings, energy-water nexus, solar hot water, heat pump, electric water heater, peak energy demand, electricity tariffs. 


\section{Introduction}

Currently, residential buildings are responsible for approximately $30 \%$ of the energy consumption in developed countries [1], with the trend forecast to increase over the coming decades [2]. The operational phase corresponds to $80-90 \%$ of the total life-cycle energy consumption of the residential sector [3].

In order to reduce the energy consumption in buildings, guidelines and regulatory frameworks were established mainly for building envelopes, heating and cooling air systems, and lighting [4,5], as well as relevant scientific studies in this branch of knowledge [6-9]. Nonetheless, hot water supply is a standard item of comfort in residential buildings in developed regions worldwide; hence, it is a key component to achieving energy and water efficiency in buildings. From a life-cycle perspective, water heating is the most energy-intensive phase of the urban water cycle, in which $84-97 \%$ of the total energy consumption for cold and hot water supplies and sewage collection, treatment and disposal is related to water heating in buildings [10-12].

Pérez-Lombard et al. [2] reported that water heating is equal to 14, 17, 22 and $26 \%$ of the total energy consumption in residential buildings in the European Union, the United States, the United Kingdom and Spain, respectively. Similarly, Boait et al. [13] and Liu et al. [14] found that water heating corresponds to $18 \%$ of the total energy consumption in standard residential buildings in the United Kingdom and the United States, respectively. In contrast, Thiers and Peuportier [15] observed that energy for water heating represents over $40 \%$ of the total energy consumption in energy efficient residential buildings in France. In Australia, Aye et al. [16] and Kenway [17] described that water heating is equivalent to 40 and $50 \%$ of the total energy consumption of homes, respectively. The more representative energy consumption for water heating reported by Thiers and Peuportier [15], Aye et al. [16] and Kenway [17] may be primarily related to the low energy demand for ambient heating and cooling in the studied building typologies. Therefore, to further enhance the energy performance of buildings, attention must be drawn to the energy performance of water heating systems [13], particularly in 
energy efficient buildings and regions with warmer climates where ambient heating is not required and natural ventilation is used.

To address the amount of energy required to heat water, new policies have been implemented to foster the use of renewable energy and energy efficient technologies to supply hot water in buildings worldwide [18]. The reduction of hot water consumption patterns has considerable potential to reduce the energy consumption associated with water in buildings [19]. Additionally, new electricity supply tariffs have been tested in order to reduce peak energy consumption. For instance, the Queensland Government in Australia committed AUD \$63 million towards tariff control and AUD \$92 million in rebate programs for residential water heating systems in the south-east Queensland (SEQ) region [20]. Moreover, SEQ electricity utilities have implemented off-peak electricity supply tariffs for water heating systems in order to reduce peak energy demand [20]. As described by Brahme et al. [21], the lifestyles of residents and the local weather conditions will considerably affect the energy performance of buildings. Therefore, notwithstanding the theoretical enhanced performance of energy efficient water heating technologies (i.e. solar and heat pumps), the feasibility of each water heating system type will depend on its energy performance under local weather conditions and hot water consumption patterns $[22,23]$. Further, the electricity supply tariff selected (i.e. all-day, controlled off-peak, night rate off-peak) may also play an important role in the performance of each system, as the supply of off-peak energy may not suit the demand patterns of a particular household. As a result, depending on the system design and operation patterns, either the capacity to deliver hot water may be constrained, or the performance of energy efficient water heating systems (i.e. solar hot water) may not be optimal. Therefore, studies addressing the effect of different electricity supply tariffs on the performance of water heating systems are crucial in order to determine the optimal strategy that combines asset and non-asset solutions. Such studies should primarily focus on the 
reduction of the total and peak energy demands of residential water heating systems without constraints in order to achieve the required level of service.

The objective of this study is to analyse the performance of residential water heating systems in the Queensland state capital city of Brisbane in Australia, for different electricity supply tariffs, hot water tank sizes, and washing machine heating source. The study analyses electric, solar and heat pump water heating technologies, considering their effect on the electricity grid (i.e. power peaks, time-distribution of energy according to electricity tariffs, and energy intensity) and their level of service (e.g. compliance rates with recommended hot water temperatures).

\section{Method}

\subsection{Overview}

The study was formulated to determine the performance of different residential water heating systems for combinations of technology type, selected electricity tariff, washing machine type, hot water tank size and weather conditions for Brisbane (Fig. 1). The study assessed three types of water heaters: (i) solar with electric back-up, (ii) heat pump, and (iii) electric. Herein, electric systems are considered systems with an electrical resistance (i.e. heating element) that converts electricity into heat. The heat pump type is an air source heat pump, of which the heat of the air at a lower temperature is pumped into water of a higher temperature. Electricity is used in all system types: in electric systems, it is the primary source of energy; in solar, it is the secondary source; and in heat pumps, it is used as the fuel to operate compressors in order to invert the heat flux from the colder air into the warmer water via a refrigeration cycle [24]. 


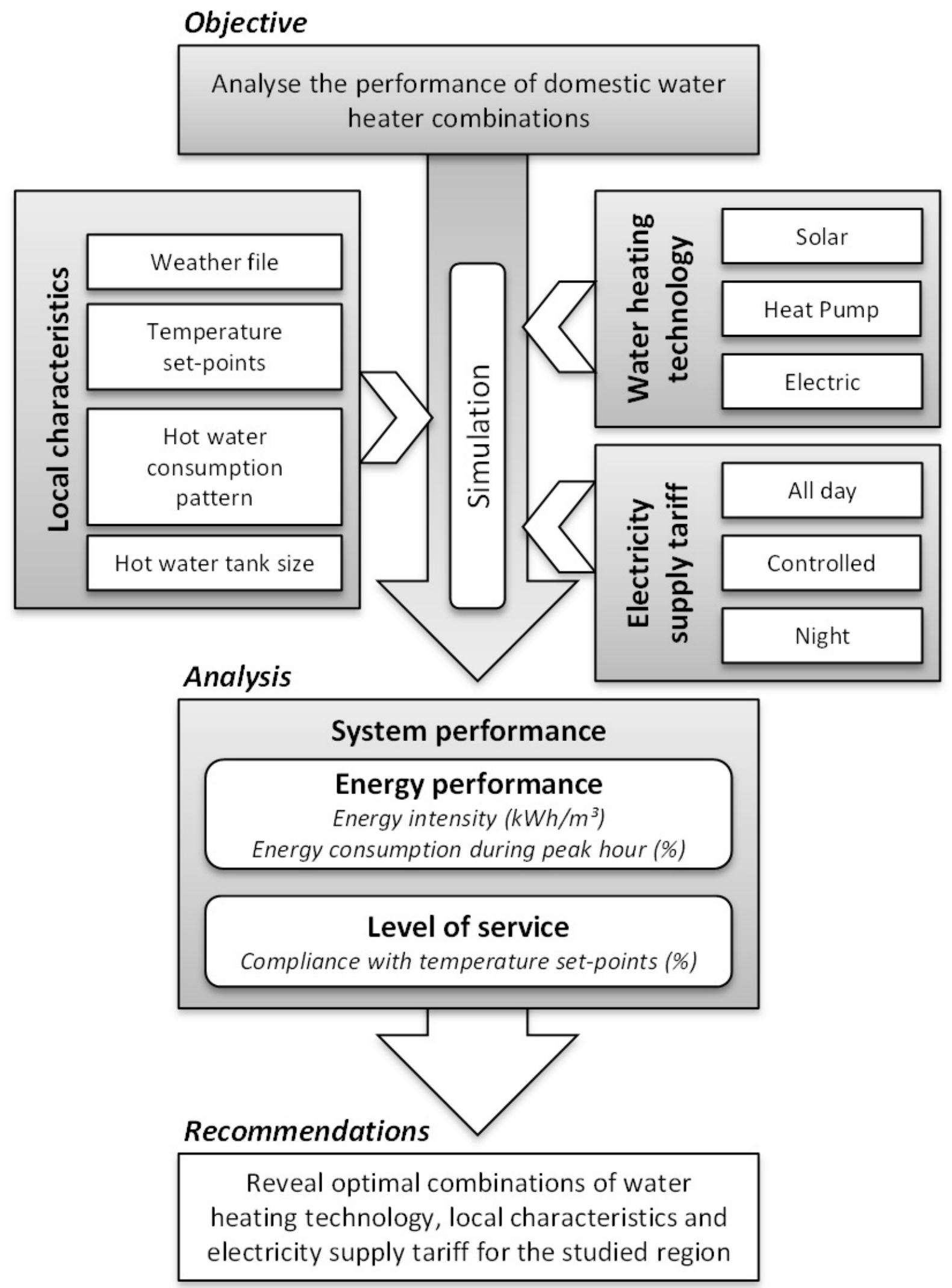

Fig. 1. Flowchart of the study method. 


\subsection{Scenarios}

For each water heating system type $(\mathrm{N}=3), 18$ scenarios were simulated (i.e. 54 scenarios in total), which took into account the combination of three tank sizes (i.e. $125 \mathrm{l}, 250 \mathrm{l}$ and $325 \mathrm{l}$ ), two hot water consumption patterns (i.e. average hot water consumption with and without washing machines: $100 \mathrm{~m}^{3} / \mathrm{year}$ [total water demand pattern] and $68 \mathrm{~m} 3 /$ year [partial water demand pattern], respectively) and three electricity supply tariff types (i.e. all-day, controlled and night). The parameters used to compose the scenarios were based on products and services available on the local market or installed in the studied households.

\subsection{Simulation software}

Simulations were carried out using the software EnergyPlus 8.1, which is open access software for energy analysis that is provided by the United States Department of Energy. This software was utilised for modelling the various scenarios in the study. A comprehensive application of the software is provided by Bojic et al. [25].

For calculations, a time step equal to one minute was applied in a similar way to other studies (e.g. Hong et al. [26]). Detailed information about the assumptions adopted in the models is provided in the following section.

\subsection{Local characteristics}

\subsubsection{Weather file}

The simulations were performed using a Representative Meteorological Year (RMY) climate file based on data recorded by the weather station located at the Brisbane Airport (WMO 945780). The RMY climate file was downloaded from the EnergyPlus website. The following climatic conditions were used as input parameters for 
the simulations: air temperature, dew point, relative humidity, sky cover, global solar radiation and diffuse solar radiation.

\subsubsection{Water temperature}

The sourced cold water temperature was estimated using the method described by Hendron et al. [27], in which the town water temperature is calculated through correlations with both the annual average outdoor air temperature (dry-bulb) (i.e. $19.9^{\circ} \mathrm{C}$ for Brisbane) and the maximum difference in the monthly average outdoor air temperature (i.e. $11.3^{\circ} \mathrm{C}$ for Brisbane). Both input values were calculated from the RMY climate file. The calculation for this parameter was performed using EnergyPlus.

The outdoor air temperature, cold water (town water supply) temperature and hot water temperature settings are illustrated in Fig. 2. These values were employed to represent the water temperature for water heating systems in Brisbane, Australia.

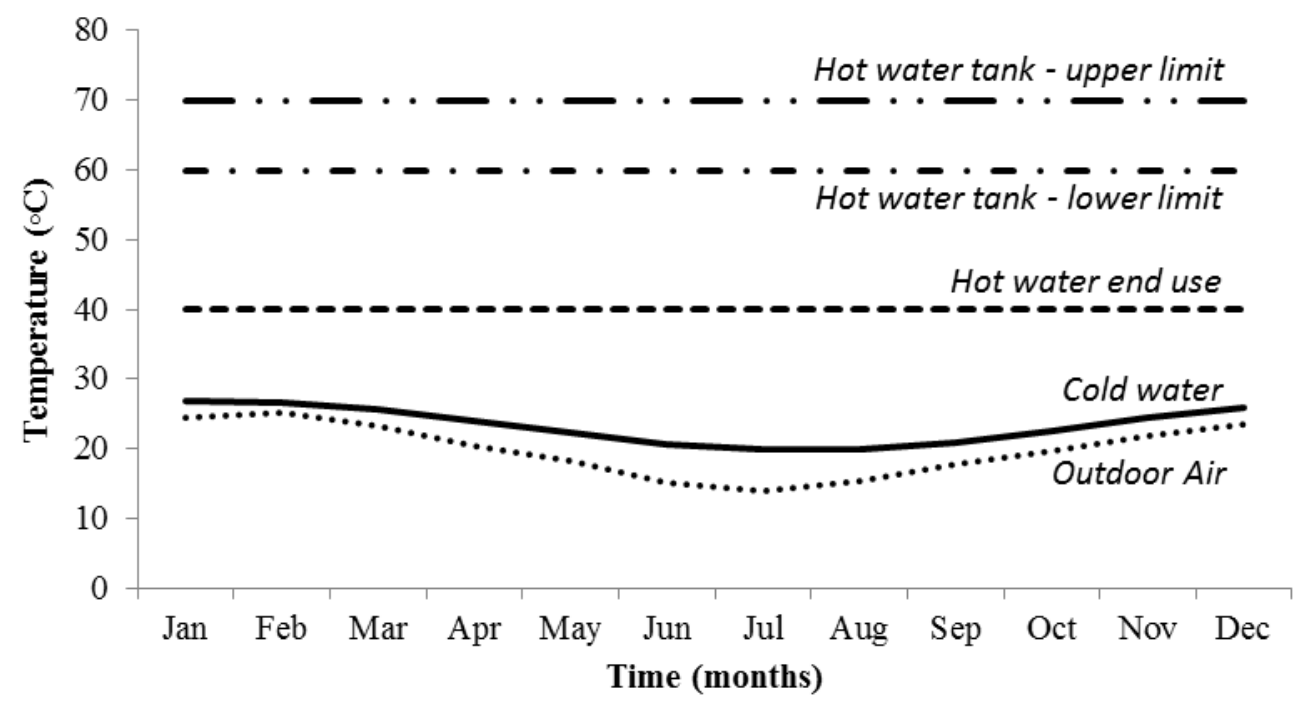

Fig. 2. Representative average temperatures for the air, cold water supply, hot water uses, and upper and lower limits of hot water tanks in Brisbane, Australia. 
The average monthly cold water temperature ranged from $19.8^{\circ} \mathrm{C}$ to $26.8^{\circ} \mathrm{C}$ and the outdoor air temperature ranged from $13.9^{\circ} \mathrm{C}$ to $25.2^{\circ} \mathrm{C}$. Despite possible variations in the temperature of different hot water end use events, the hot water end use (e.g. shower, bath, tap, and washing machine) was set to a constant temperature of $40.0^{\circ} \mathrm{C}$ for the purpose of this study, as suggested in other studies [27-29].

As widely described in the literature, temperatures over $55^{\circ} \mathrm{C}$ inhibit the growth of Legionella sp. [30-32]. Therefore, to control the proliferation of Legionnaire's disease in systems with hot water storage, the Australian and New Zealand Standard for Heated Water Services (AS/NZS 3500.4.2:2003) sets a minimum temperature of $60{ }^{\circ} \mathrm{C}$ for hot water tanks [33]. In contrast, temperatures above $70{ }^{\circ} \mathrm{C}$ may damage the lining of vitreous enamel storage tanks [34]. Therefore, in this study, a temperature set-point ranging from $60{ }^{\circ} \mathrm{C}$ to $70{ }^{\circ} \mathrm{C}$ was adopted for hot water tanks.

\subsubsection{Hot water consumption patterns}

Hot water consumption patterns were obtained from the SEQ Residential End Use Study (SEQREUS) [35], in which a smart metering data acquisition process and subsequent water end use classification method was used as described in detail by Willis et al. [36] and Beal and Stewart [37]. In the present study, available data associated with the SEQREUS was used for the hot water end uses of 12 Brisbane households in winter and summer in 2010 as described in supplementary document (Appendix A).

The performance of water heating systems was analysed considering two representative water consumption patterns for households in Brisbane, including: (i) partial water consumption pattern (i.e. hot water supply to shower, baths and taps) - 68 m³/year; and (ii) total water consumption patter (i.e. hot water supply to washing machines, shower, baths and taps) - $100 \mathrm{~m}^{3} /$ year. 


\subsubsection{Hot water tank size}

Information regarding the type, model and size of water heating systems installed in Brisbane households was collected during site visits carried out for the SEQREUS [35]. These data were used to determine the most prevalent type of water heating system with a primary or secondary heating source powered by electricity (e.g. electric, electric-boosted solar and heat pump water heating systems) among the studied households.

In total, information about the nominal capacity of hot water tanks of 27 households in Brisbane was used in this study. The number of residents in the households varied from one to seven people, with an average of three people per household. The household size and water heating system size and type were used to determine a representative nominal capacity of hot water tanks for each water heating system type among the studied households.

Statistical analyses were carried out to determine the influence of the number of residents per household on the nominal capacity of hot water tanks installed in the assessed households. For this purpose, two analyses were performed: (i) correlation between number of residents and nominal capacity of hot water tanks; and (ii) single factor analysis of variance (ANOVA), which considered the variance of the nominal capacity of hot water tanks among three different populations (i.e. households with 1-2 residents, 3-4 residents and $>4$ residents) for a $95 \%$ confidence interval.

For each water heating system type, the nominal capacity of hot water tanks was classified into eight intervals of $50 \mathrm{l}$, from $100 \mathrm{l}$ to $500 \mathrm{l}$. The mean value of the most prevalent nominal capacity interval for each water heating type was adopted as the representative among the studied households. These nominal capacities of hot water tanks were used to carry out the analysis for all water heating system types.

For all system types, model simulations were performed considering the volume of hot water tanks to be $10 \%$ lower than their nominal capacity as suggested by Burch and Erickson [38]. Moreover, the models were 
performed considering the stratification of water into six nodes (volume of water with a single temperature) of equal volume within hot water tanks. It was assumed that hot water tanks were positioned vertically for electric and heat pump water heating systems, and, horizontally, for solar water heating system.

\subsection{Operational assumptions and technical specifications of water heating systems}

The technical specification of the most prevalent model for each water heating system type, among the 27

households assessed, was taken into account to carry out simulations. Technical specifications of the selected models were obtained from the websites of their respective manufacturers. The performance curves of the heat pump compressor and evaporator, as well as of the solar collector, were obtained from template and library files available using the EnergyPlus software.

The hot water tank heat loss was calculated based on the technical specifications of the insulation materials for this component. Heat losses in the distribution system (i.e. pipes) were not taken into account. Parasitic power loss rates were considered equal to $10 \mathrm{~W}$, which is mainly attributed to stand-by power consumption. This assumption was based on the upper standby power range described by Guan et al. [39].

\subsection{Electricity supply tariff selection}

Currently, the energy distributor servicing the Brisbane region supplies residential buildings with three different electricity supply tariffs for water heating systems listed in order of most to least expensive: (i) all-day (i.e. 24 hours continuous supply); (ii) controlled (i.e. at least 18 hours supply with interruption during peak hours); and (iii) night (i.e. eight hours supply during the late night). 
This information was obtained via telephone contact with the electricity distributor for the city of Brisbane (i.e.

Energex). They also advised that intermittent supplies (i.e. controlled and night rate tariffs) may vary their

electricity supply periods daily, depending on the peak hour demand for each day.

Notwithstanding the variable nature of electricity supply periods for intermittent electricity supply tariffs, a fixed

most-likely schedule throughout the year was adopted to characterise them. For the controlled supply scheme,

interruptions in the electricity supply were set from 7 am to 9 am and from 4 pm to 8 pm, whereas for the night

supply scheme, interruption was set from 6 am to $10 \mathrm{pm}$. Simulations were carried out considering these three

electricity supply tariff arrangements for each studied water heating system type.

\subsection{Water heating system performance evaluation criteria}

The performance of the modelled systems in each scenario were analysed considering both the energy

performance of water heating systems (i.e. power peaks, time-distribution of energy demand, and energy

intensity) and their level of service (i.e. compliance rates with recommended hot water temperatures). Each of

these performance evaluation categories and sub-categories are discussed in detail in the following sections.

\subsubsection{Energy performance}

Energy performance was assessed in terms of energy intensity (i.e. unit of energy per unit of water in $\mathrm{kWh} / \mathrm{m}^{3}$ )

and power peaks (i.e. percentage (\%) of the total energy usage during peak hours).

The energy intensity of the simulated systems was calculated as per Eq. (1):

$$
E I_{n}=\frac{\int_{0}^{t} P d t}{\int_{0}^{t} Q d t}
$$


where $E I_{n}$ is the energy intensity of the water heating system $\left(\mathrm{kWh} / \mathrm{m}^{3}\right) ; P$ is the instantaneous power rate of the system (kW); $Q$ is the instantaneous water flow rate consumption ( $\left.\mathrm{m}^{3} / \mathrm{min}\right)$; and $t$ is the time elapsed (min).

The total energy intensity of the hot water supply in households with front load washing machines was calculated taking into account the energy intensities of both the domestic water heating system under the partial water consumption pattern, and of the internal water heating system of washing machines through Eq. (2). This equation also takes into account the potential reduction of the energy intensity promoted by water savings in a front load washing machine with internal heating elements.

$$
E I_{t}=\sum_{i=1}^{n}\left(\frac{E I_{n} \times D_{n} \times\left(1-s_{n}\right)}{D_{t}}\right)
$$

where $E I_{t}$ is the total energy intensity of the hot water supply $\left(\mathrm{kWh} / \mathrm{m}^{3}\right)$; is the energy intensity of the water heating system "n" $\left(\mathrm{kWh} / \mathrm{m}^{3}\right) ; D_{n}$ is the hot water demand met by the water heating system "n" (m³/year); $s_{n}$ is the water saving potential achieved when using water heating system "n"; $D_{t}$ is the total hot water demand.

Pursuant to the energy tariff description provided by the local energy distributor (i.e. Energex), electricity supply hours were classified into three periods: (i) 'off peak', from $10 \mathrm{pm}$ to $7 \mathrm{am}$; (ii) 'shoulder', from 7 am to 4 pm and from 8 pm to $10 \mathrm{pm}$; and (iii) 'peak', from $4 \mathrm{pm}$ to $8 \mathrm{pm}$. The amount of energy consumed by systems during peak, shoulder and off-peak periods was calculated in accordance with Eq. (3):

$$
E C_{i}=\frac{E_{i}}{E_{t}} \times 100
$$


where $E C_{i}$ is the percentage of energy consumption within the period ' $i$ ' (\%); $E_{i}$ is the energy consumption within the period ' $i$ ' (kWh); and $E_{t}$ is the total energy consumption (kWh).

\subsubsection{Level of service}

The level of service (i.e. hot water supply capacity) was determined by assessing the compliance of systems against two parameters: (i) end use temperature $\left(40^{\circ} \mathrm{C}\right)$; and (ii) tank lower temperature $\left(>60^{\circ} \mathrm{C}\right)$. These parameters are crucial for the provision of hot water, as non-compliance may lead to both a reduction in hot water supply comfort and health risks arising from Legionnaire’s disease.

Temperatures were classified into nine water temperature intervals. The closer a temperature interval was from the hot water end use temperature set-point, the shorter was its interval range. This procedure was adopted to detail temperature ranges in which hot water is more likely to be used (i.e. 30 and $40{ }^{\circ} \mathrm{C}$ ) at end use points. Based on this assumption, the following temperature $\left({ }^{\circ} \mathrm{C}\right)$ intervals were established: (i) 18.0-30.0; (ii) 30.1-34.0; (iii) 34.1 to 37.0 ; (iv) 37.1 to 40.0 ; (v) 40.1 to 50.0 ; (vi) 50.1 to 60.0 ; (vii) 60.1 to 70.0 ; (viii) 70.1 to 80.0 ; and (ix) 80.1 to 90.0 .

The percentage of hot water availability for each temperature interval was calculated using Eq. (4):

$$
W A_{i}=\frac{T_{i}}{T_{t}} \times 100
$$

where $W A_{i}$ is the percentage of water availability within the temperature interval ' $i$ ' (\%); $T_{i}$ is the total time with temperature within interval ' $i$ ' (min); and $T_{t}$ is the total time elapsed (min). 
The amount of time in which systems complied with the temperature set-points was calculated by summing the total period for which systems complied with the specified temperature thresholds.

\subsubsection{Water heating system performance evaluation framework}

The performance of each modelled scenario was classified in accordance with a developed evaluation framework incorporating four parameters, two within the category Energy Performance (i.e. electricity consumption at grid peak hours, and hot water services energy intensity), and two within the category Level of Service (i.e. end use temperature compliance, and tank lower temperature compliance).

The energy intensity of hot water supply services was calculated using Eq. (2), and when applicable took into account a set-point temperature of $40{ }^{\circ} \mathrm{C}$ for washing cycles as well as water savings of $36 \%$ in front load washing machines with internal heating element. This water saving potential was based on the study carried out by Beal and Stewart [35]. The other parameters were calculated considering the performance of domestic water heating systems only.

In this evaluation framework, equal weights were attributed to all assessed parameters, as their combination allows for a holistic analysis of the performance of water heaters taking into account health, comfort and energy efficiency principles. For this purpose, three levels of performance were determined, with an associated score for each assessed parameter equal to Optimal -2.50 points, Intermediate -1.25 point, and Poor -0.00 points. The final score of each scenario was calculated by summing the scores obtained for each of the four performance parameters. Therefore, the maximum possible score for the assessed water heating systems was equal to ten points, while the minimum, zero points.

The classification system was determined in accordance with the internal variability of values encountered for a specific parameter. The highest and lowest performance levels were considered by dividing the calculated 
performances into upper and lower quartiles; whereas intermediate performance levels were attributed to values in the interquartile range. By doing so, the performance of water heaters was benchmarked against the best results found for each parameter assessed.

\section{Result and discussion}

\subsection{Local characteristics}

\subsubsection{Hot water tank sizing}

The advantage of water heating systems that utilise storage tanks relate to their capacity to heat water to a set-point temperature using a reduced power rating heating element at off-peak times or through renewable energy sources (i.e. solar) without drawing excessive amounts of energy from the grid during peak hour periods, as is often the case for instantaneous water heating systems. However, hot water storage tanks require adequate size selection in order to promote continuous and safe supply of hot water for households while using energy optimally. For example, oversized storages give rise to higher heat losses, while undersized storages may result in an inability to achieve required the set-point temperatures and a much higher utilisation of electricity consumption at peak periods to heat water.

Among the studied household groups (i.e. households with 1-2 residents, 3-4 residents and over 4 residents), there was not a significant difference in their hot water tank capacity $(p=0.271)$ for a $95 \%$ confidence interval. The number of residents and the water heating tank size of the studied houses were not correlated $\left(R^{2}=0.035\right)$; and actually showed an insignificant trend of smaller storages for larger household sizes. This finding is counterintuitive, as the tank size should be a function of the hot water demand (i.e. larger tank size with more residents per household).

Likely, this lack of correlation would be attributed to: (i) new residents moving into a house with an existing hot 
water heating system sized to a smaller household; (ii) developers under sizing systems to reduce implementation costs; or (iii) the deliberate selection of undersized tanks by householders due to financial constraints. This issue may be overcome by enforcing the installation of water heating systems with a tank storage capacity that is optimal for the occupancy rate designed for the building/apartment.

The tank water size interval with the highest frequency for electric water heating systems was $\geq 100$ and $<150$ l, while for solar and heat pump systems, it was $\geq 300$ and $<350$ l. Therefore, hot water tank with a nominal capacity of $125 \mathrm{l}$ and $325 \mathrm{l}$ were analysed in the study so as to explore the range of systems predominantly utilised among the studied households. As the number of residents did not affect the nominal capacity of hot water tanks among the studied population, it was assumed that $125 \mathrm{l}$ and 3251 hot water tanks alike can be used to supply hot water for a representative household size in Brisbane with an average population of 3 residents. In addition to the two empirically determined hot water tank nominal capacities, models were also performed for 2501 hot water tanks, which is the recommended minimal tank size for water heaters at households with 3-4 residents in Australia [34].

In 2010, the most frequent water heating system type among assessed homes in Brisbane was electric. Despite the prevalence of electric systems in the total housing stock in Brisbane, it is likely that solar and heat pump system will be more frequent in the new building stock constructed in the last five years in the region.

Nonetheless, this transition may not occur immediately as electric systems typically have a lower capital cost and maintenance requirement, as well as a greater reliability to provide hot water in all weather conditions, compared with solar and heat pump systems. These differences will depend on the electricity tariffs, as the economic feasibility of energy efficient systems (e.g. solar and heat pump) will be mostly associated with a reduction in operational costs in comparison to electric systems. 


\subsubsection{Technical specifications of water heating systems}

The technical specifications of the three studied water heaters (i.e. solar, electric and heat pump) were used to model the systems. The models for solar heating systems were developed considering an ideal north-facing orientation and a tilt angle equal to the local latitude (i.e. $27.2^{\circ}$ in Brisbane) in accordance with the Plumber Reference Guide [34]. By contacting the local retailers of solar systems, the most common solar system model for the Brisbane region was defined as a $300 \mathrm{l}$ hot water tank with an electric booster of $1800 \mathrm{~W}$ and two solar collectors with copper risers and a black polyester powder-coated aluminium absorber. The performance variables of the modelled collector are presented in Table 1.

\section{Table 1}

Technical specification of the solar collectors.

\begin{tabular}{|c|c|}
\hline Parameter & Value \\
\hline Number of collectors & 2 \\
\hline Gross area (m²/collector) & 1.983 \\
\hline Test fluid & Water \\
\hline Test flow rate $(\mathrm{l} / \mathrm{s})$ & 0.037 \\
\hline Test correlation type & Inlet \\
\hline Coefficient 1 of collector efficiency (dimensionless) & 0.608 \\
\hline Coefficient 2 of collector efficiency $\quad\left(\mathrm{W} /\left(\mathrm{m}^{2} \cdot \mathrm{K}\right)\right)$ & -5.4707 \\
\hline Coefficient 3 of collector efficiency $\quad\left(\mathrm{W} /\left(\mathrm{m}^{2} \cdot \mathrm{K}^{2}\right)\right)$ & -0.0271 \\
\hline Coefficient 2 of incident angle modifier (dimensionless) & -0.1718 \\
\hline Coefficient 3 of incident angle modifier (dimensionless) & -0.058 \\
\hline
\end{tabular}

The power rating of heating elements of the electric system was assumed to be equal to $3600 \mathrm{~W}$. This rate was based on the manufacturers' specifications. The conversion efficiency of electricity into heat by heating elements of electric and solar water heating systems was considered equal to $100 \%$ as described by Burch and Erickson [38]. The specification of the heat pump water heater modelled is presented in Table 2. 


\section{Table 2}

Technical specifications of the heat pump.

\begin{tabular}{lr}
\hline Parameter & Value \\
\hline Rated heating capacity $(\mathrm{W})$ & 3600 \\
Rated coefficient of performance $(\mathrm{W} / \mathrm{W})$ & 4.0 \\
Minimum inlet air temperature for compressor operation $\left({ }^{\circ} \mathrm{C}\right)$ & 11 \\
Compressor location & Outdoors \\
Secondary heating element $(\mathrm{W})$ & 0 \\
\hline
\end{tabular}

The reviewed technical specifications indicated a standard insulation of glass wool with 38 mm thickness for hot water tanks. This insulation was adopted to estimate conduction heat losses on tanks. As the thermal conductivity of glass wool is approximately $0.04 \mathrm{~W} /(\mathrm{m} \cdot \mathrm{K})$ and the thickness of the insulation was $38 \mathrm{~mm}$, the heat loss coefficient was considered equal to $1 \mathrm{~W} / \mathrm{K}$.

\subsection{Systems performance}

\subsubsection{Electric system}

In general, the energy demand for electric water heating systems varied considerably among the different scenarios. The estimated annual average daily water consumption and power peaks of electric water heating systems are illustrated in Fig. 3. 


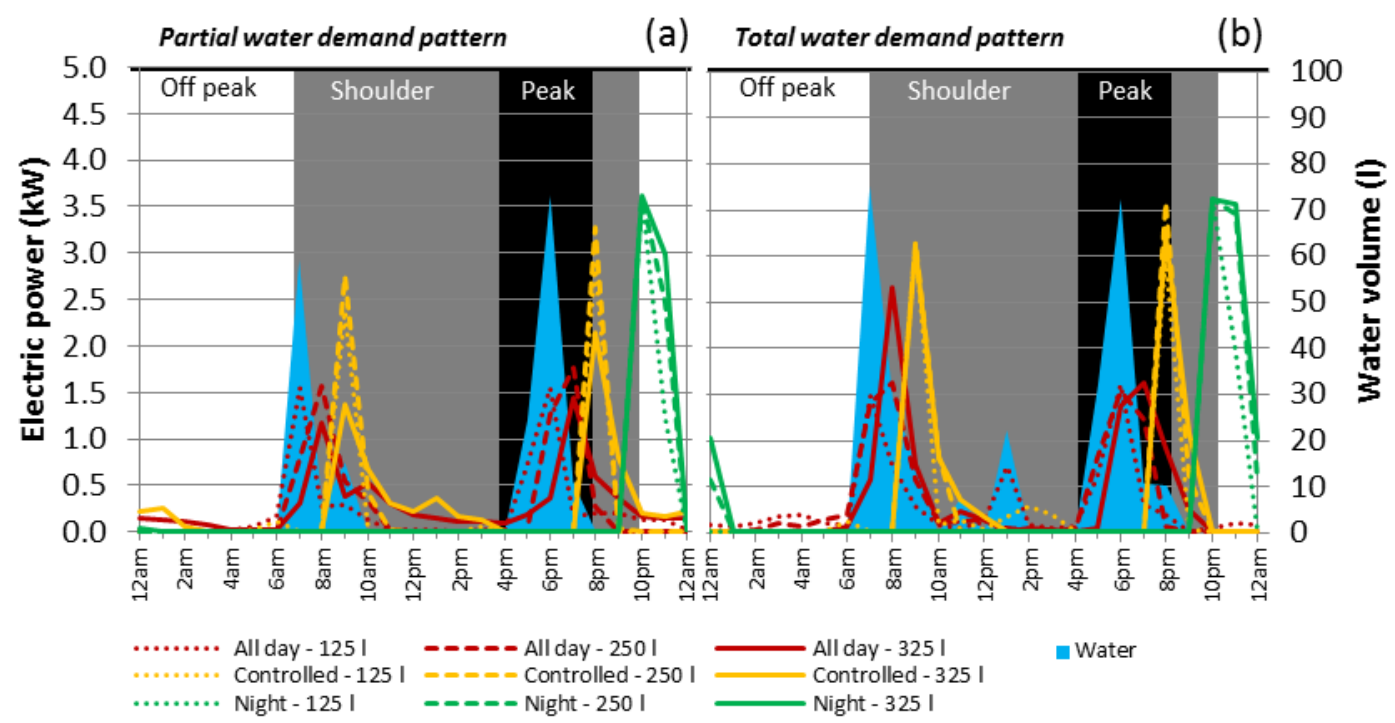

Fig. 3. Electric water heater annual average water and energy demand patterns under different scenarios: tank sizes of 125, 250 and 325 l, partial and total water demand patterns, and all-day, controlled and night off-peak electricity tariffs.

A significant fraction of the water demand occurred within the grid peak electricity demand from 4pm to 8pm.

For the different electricity tariffs, power peaks occurred at different times, in which the power peak occurred after water consumption peaks for systems with all-day electricity supply, and immediately after power reestablishment for systems with intermittent electricity supply (i.e. controlled and off-peak tariffs). Electric supply for systems connected to all-day power tariffs occurred during grid peak electricity hours 29 to $45 \%$ of the times Fig. 4a. 


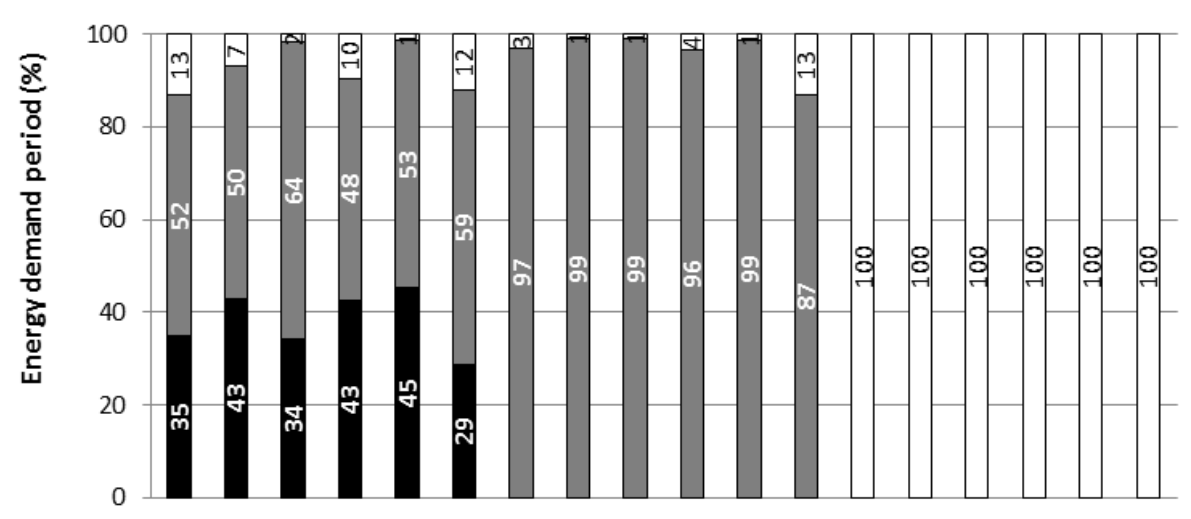

(a)

口Off peak

口Shoulder

- Peak

(b)

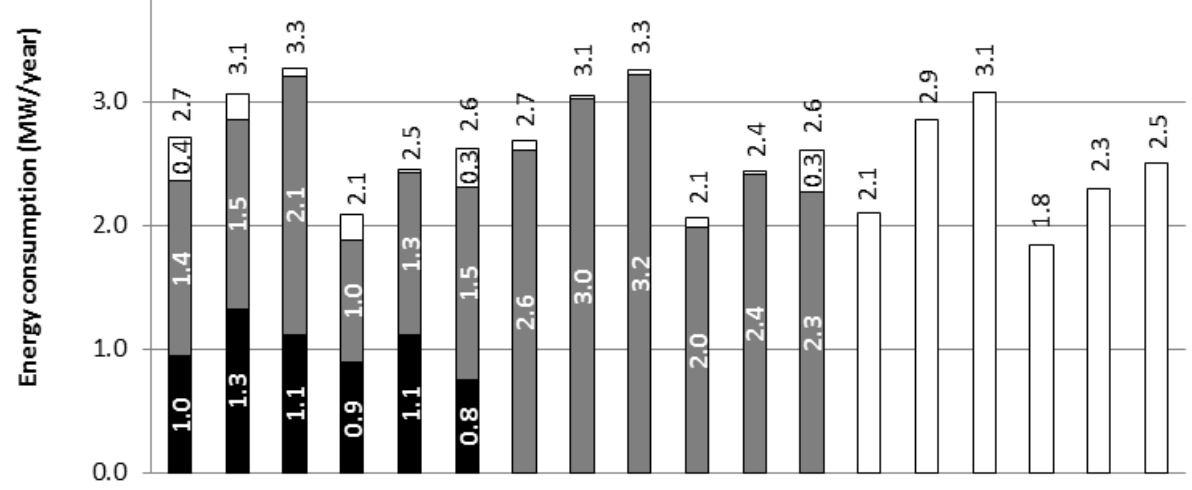

(c)

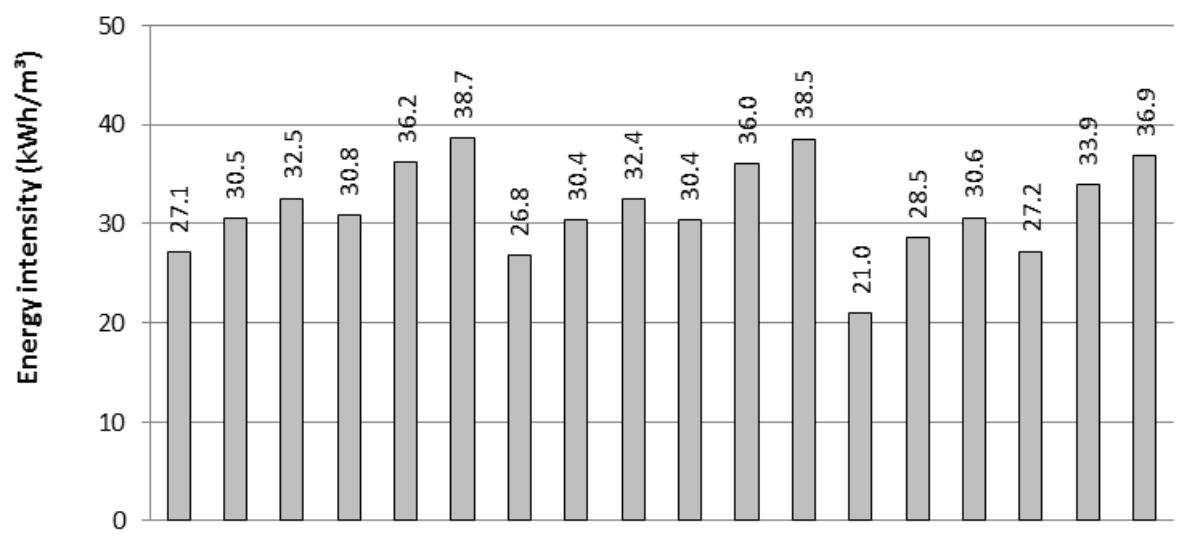

(d)

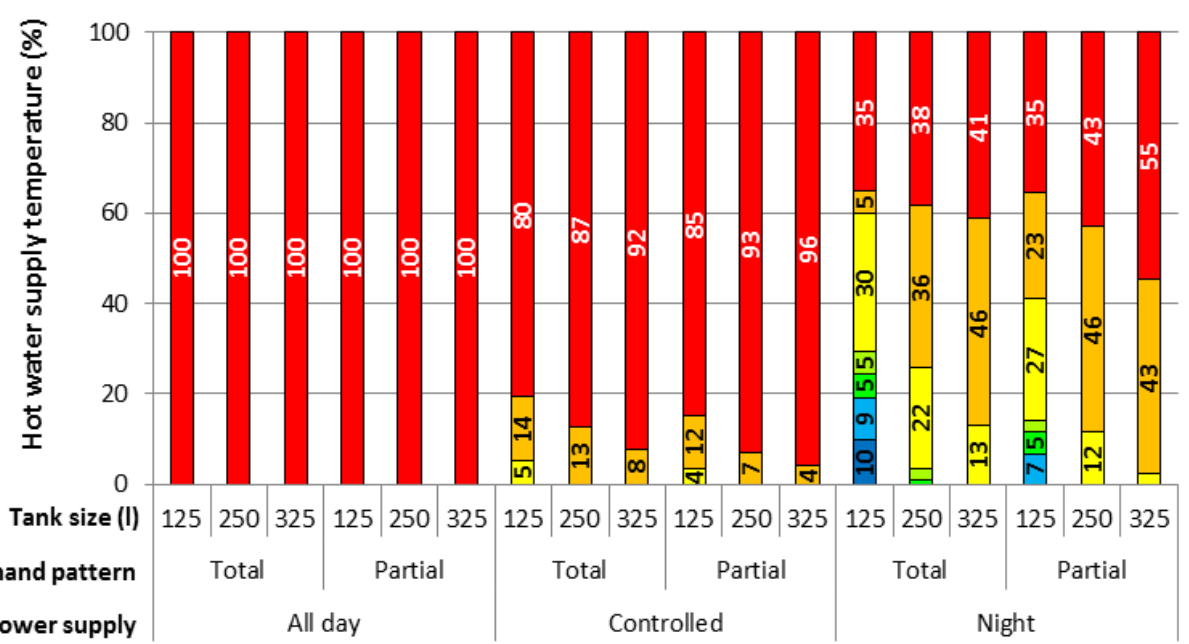

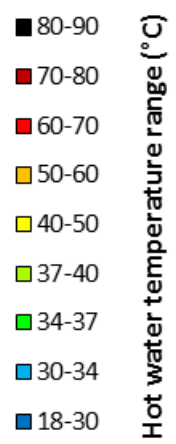


Fig. 4. Electric water heater annual average peak electricity demand (a), annual energy consumption (b), energy intensity (c) and hot water supply capacity (d) under different scenarios: tank sizes of 125, 250 and 325 l, partial and total water demand pattern, and all-day, controlled and night off-peak electricity tariffs.

The annual energy consumption of electric systems was equal to 2.3 and $2.9 \mathrm{MWh} / \mathrm{hh}$ on average for the partial and total water consumption patterns, respectively. Electric systems increased their energy consumption when larger hot water tank capacities were used. This can be attributed primarily to higher heat losses in larger tanks. Moreover, when electric systems were under capacity to supply hot water services (e.g. systems with $125 \mathrm{l}$ tanks and connected to off-peak electricity tariffs [Fig. 4d]), the energy consumption was reduced as systems supplied water at a lower temperature than the set-point temperature.

The energy intensity of electric systems was equal to $31.6 \mathrm{kWh} / \mathrm{m}^{3}$ on average, ranging from 21.0 to 38.7

$\mathrm{kWh} / \mathrm{m}^{3}$ (Fig. 4c). From an energy intensity perspective, total water consumption pattern scenarios were, on average, $5 \mathrm{kWh} / \mathrm{m}^{3}$ (19 \%) more efficient than the partial water patterns, in which hot water is not supplied to washing machines. The lower energy intensity of systems under the total consumption patterns is mainly attributed to the detention time of hot water in tanks. The longer the detention time, the more heat lost from a volume of hot water. This, in turn, leads to reheating requirements, which increase the amount of energy embodied in the hot water. Similarly to the energy consumption, the energy intensity had an upward trend with an increase of the hot water tank capacity.

The energy intensity difference of partial and total hot water supply systems was even more pronounced when the energy consumption of front load washing machines with internal heating elements were taken into account. For instance, considering the cold water temperature pattern of the Brisbane region, washing machines produce hot water at an energy intensity of 45.3 and $82.0 \mathrm{kWh} / \mathrm{m}^{3}$ when high water temperature set-points of 60 and 
$90{ }^{\circ} \mathrm{C}$ are used in washing cycles, respectively. However, if washing cycles are set to $40{ }^{\circ} \mathrm{C}$, the energy intensity will be approximate $20.8 \mathrm{kWh} / \mathrm{m}^{3}$.

By considering the average water consumption pattern of washing machines in the studied households (i.e. 32.6 $\mathrm{m}^{3} /$ year), the energy consumption for hot water supply would have a respective increase of approximately 0.1 , 0.9 and $2.1 \mathrm{MWh} / \mathrm{hh} /$ year on average when front load washing machines with washing cycles set to 40, 60 and $90{ }^{\circ} \mathrm{C}$ are used in place of supplying hot water at $40^{\circ} \mathrm{C}$ from electric water heating systems to washing machines without internal heating element. Nonetheless, this increase in the energy consumption could be limited by water savings promoted by front load washing machines. For instance, Beal and Stewart [35] reported that front load washing machines are on average $36 \%$ more water efficient than the washing machines with the lowest water efficient rating in Australia. Taking into consideration this water saving potential, the use of front load washing machines set to $40^{\circ} \mathrm{C}$ washing cycles would promote an average reduction of $0.1 \mathrm{MWh} / \mathrm{hh} / \mathrm{year}$ in the energy consumption for hot water supply at the studied households. In contrast, if washing cycles were set to 60 and $90{ }^{\circ} \mathrm{C}$, the use of front load washing machines would still give rise to an increase of 0.4 and $1.1 \mathrm{MWh} / \mathrm{hh} / \mathrm{year}$, respectively.

Only electric systems with a continuous electricity supply complied at all times with the temperature set-point for hot water tanks $\left(60-70^{\circ} \mathrm{C}\right)$. The compliance levels dropped to between 80 and $96 \%$ for systems connected to controlled electricity supply. The compliance declined considerably in the night electricity supply tariff, when the hot water tank temperature was below the $60{ }^{\circ} \mathrm{C}$ set-point temperature $45-65 \%$ of the time. Depending on site specific conditions, the non-compliance with the $60{ }^{\circ} \mathrm{C}$ hot water threshold in hot water tanks may promote Legionella outbreaks. Nonetheless, as described by Serrano-Suárez et al. [31], the growth of Legionella is multifactorial, and depends not only on temperature ranges, but also on the microbial and physicochemical characteristics of each system. Factors such as biofilm formation are directly correlated with 
Legionella growth, as heterotrophic bacteria and protozoa may protect Legionella from intermittent harsh conditions (i.e. temperatures over $55^{\circ} \mathrm{C}$ ) [31]. This may be linked with the findings of Mathys et al. [40], who observed that among 400 residential water heating systems with hot water tanks in Germany, Legionella was present only in systems with more than 2 years of operation. Therefore, extended periods of non-compliance with the $60^{\circ} \mathrm{C}$ temperature threshold may promote health risks associated with Legionnaires’ diseases predominantly in older water heating systems due to biofilm formation.

All electric system scenarios complied with the hot water tank end use set-point temperature $\left(40^{\circ} \mathrm{C}\right)$, except for systems with $125 \mathrm{l}$ tanks and night electricity supply tariffs. For these systems, the water temperature was under the temperature set-point 15 and $30 \%$ of the time for the partial and total water consumption patterns, respectively. The reported minimum hot water tank sizes for households with 3 residents and electric water heating systems connected to controlled and night off-peak tariffs are 125 and 250 l, respectively, as per the local energy distributor [41]. The models presented in this study show that the tank sizes recommended by the local energy distributor are adequate for the hot water end use set-point of $40{ }^{\circ} \mathrm{C}$ even when systems are under the total water demand pattern (275 l/hh/d or 100.4 myear). Moreover, the models confirmed the existence of non-compliant events of electric water heating systems design out of specification (e.g. electric water heating system with $125 \mathrm{l}$ tank connected to night off-peak tariff).

By using controlled energy supply schemes, the compliance rate with recommended hot water temperatures of electric systems did not decline significantly (Fig. 4d), and between 0.8 and $1.3 \mathrm{MWh} / \mathrm{hh} / \mathrm{year}$ of the energy consumption could be diverted from peak hours to shoulder or off-peak hours of the electricity grid (Fig. 4b).

\subsection{Solar system}


Solar water heating systems promoted a significant reduction of power peaks in relation to electric systems, as

electricity supply is used only as a back-up energy source. Fig. 5 illustrates the daily average power peaks of the modelled solar water heating systems for a representative household in Brisbane.

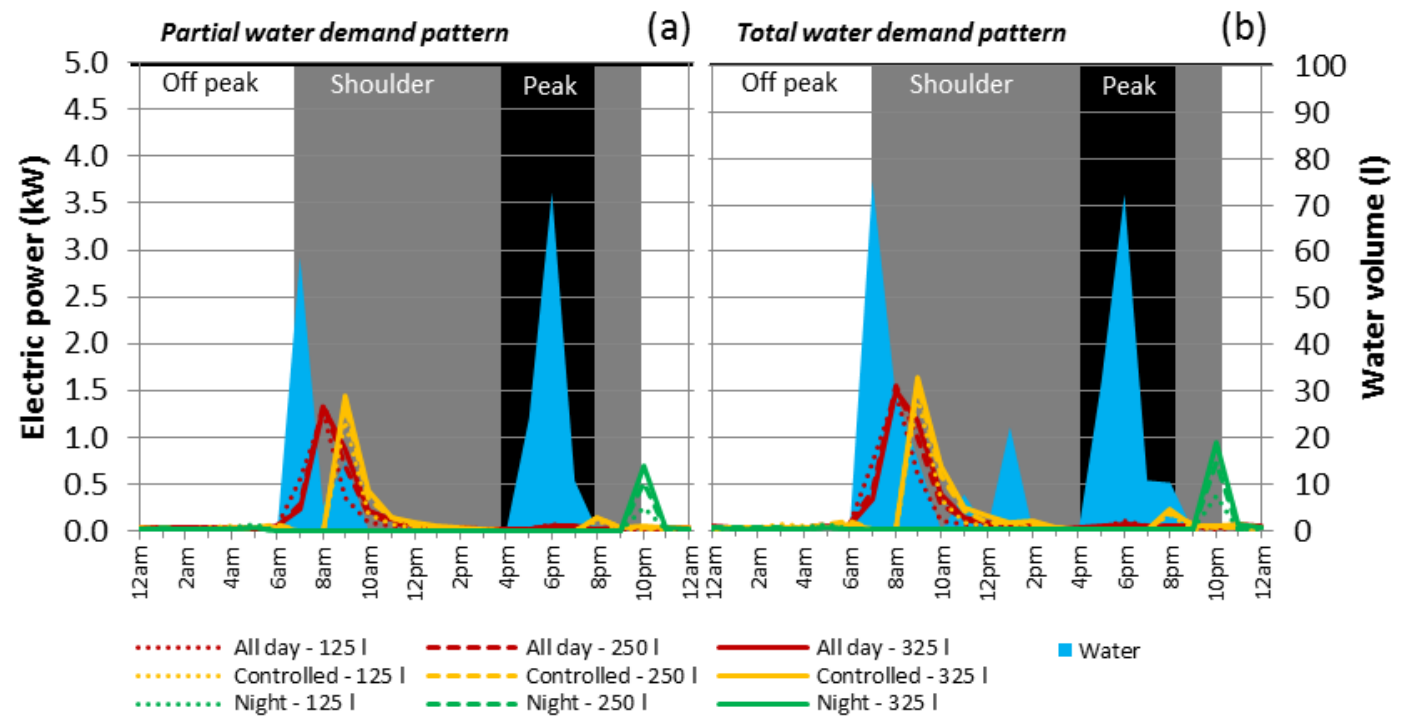

Fig. 5. Solar water heater annual average water and energy demand patterns under different scenarios: tank sizes of 125, 250 and 325 l, partial and total water demand patterns, and all-day, controlled and night off-peak electricity tariffs.

The power peak for solar systems connected to all-day and controlled electricity tariffs took place predominantly after the morning water peak consumption, whereas night peaks occurred only for systems connected to the night off-peak tariff. The electricity consumption during peak hour times was minimal for solar systems connected to all-day electricity supply, varying from 4 to $5 \%$ out of the total electricity consumption, as most of the electricity consumption (i.e. approximately 86 \%) occurred during shoulder hours for the electricity grid. Similar results were observed for solar systems connected to controlled electricity supply, in which 86 to $90 \%$ of the electricity consumption occurred during shoulder hours (Fig. 6a). 


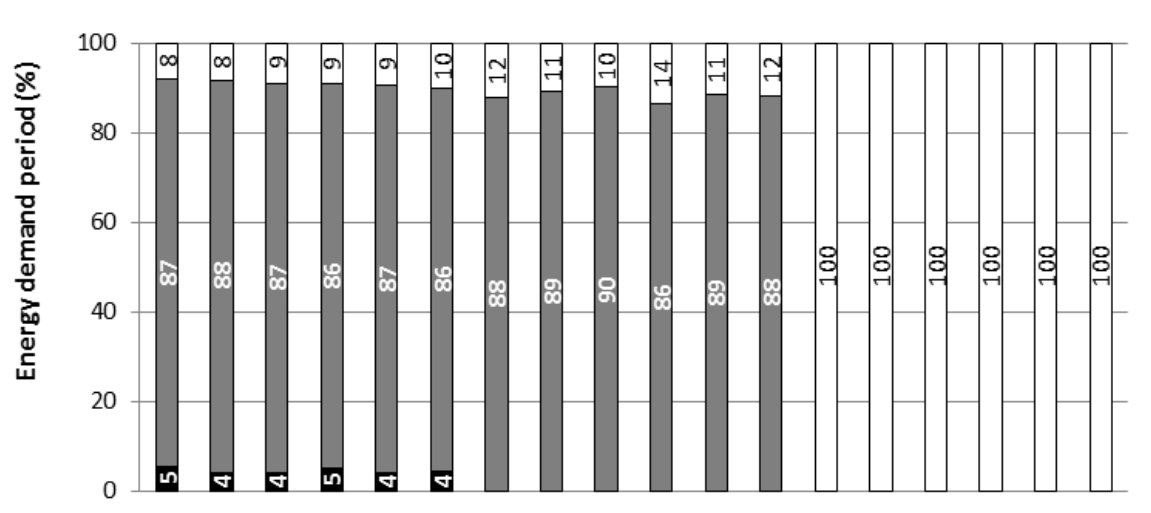

(a)

$\square$ Off peak

口Shoulder

- Peak

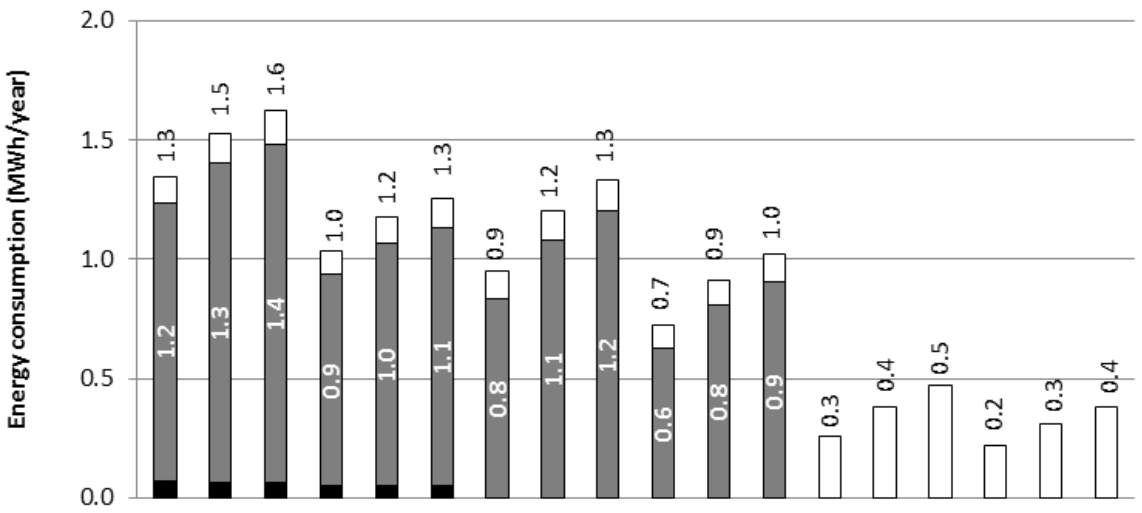

(b)

口Off peak

口Shoulder

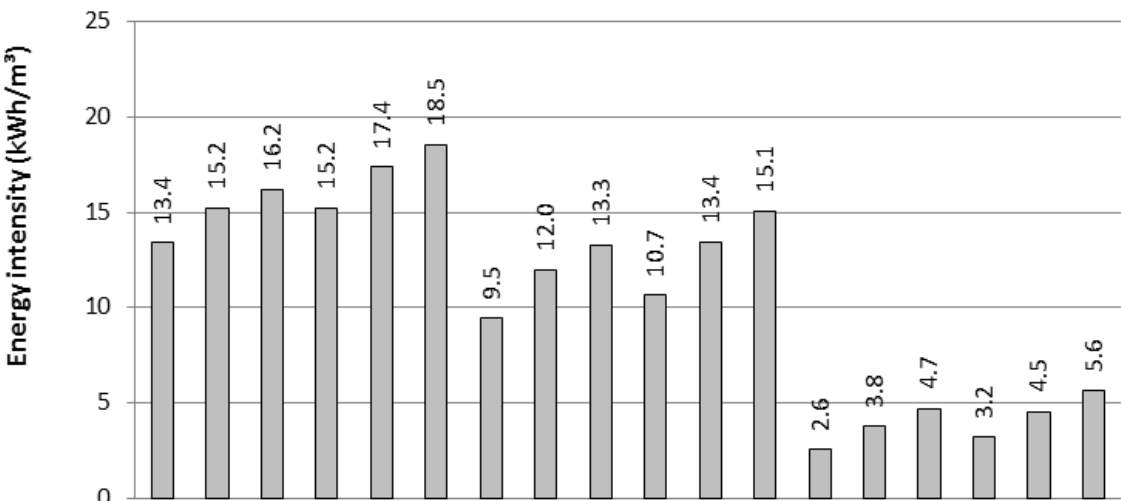

(c)

(d)

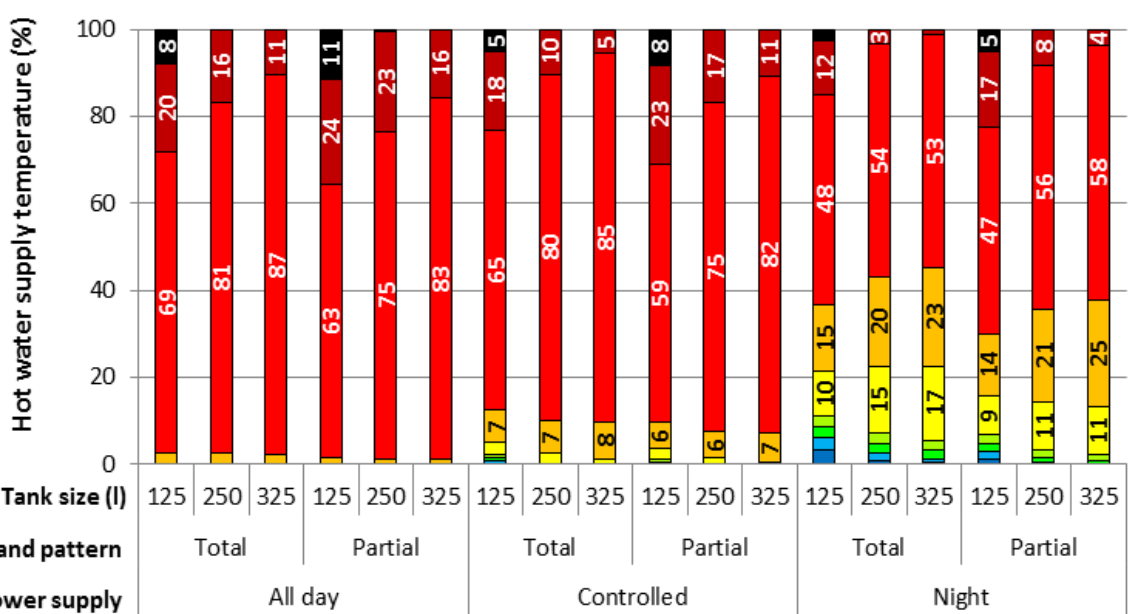

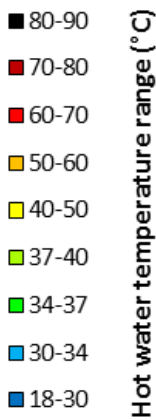

Demand pattern

Power supply

All day

Controlled 
Fig. 6. Solar water heater annual average peak electricity demand (a), annual energy consumption (b), energy intensity (c) and hot water supply capacity (d) under different scenarios: tank sizes of 125, 250 and 325 l, partial and total water demand pattern, and all-day, controlled and night off-peak electricity tariffs.

The electricity consumption of solar systems was on average 0.8 and $1.0 \mathrm{MWh} / \mathrm{hh} / \mathrm{year}$ for the partial and total water consumption patterns, respectively, ranging from 0.2 to $1.6 \mathrm{MWh} / \mathrm{hh} /$ year (Fig. 6b). As with electric water heating systems, solar systems with larger hot water tanks consumed more electricity mainly due heat losses. However, the electricity consumption increase was not as pronounced as in electric systems, because solar systems can both heat water at higher temperatures than the set-point temperature, and promote continuous heating when solar radiance is available.

The combination of solar hot water supply to hot water end uses considered into the partial water consumption pattern with front load washing machines with internal heating promoted an average increase of the electricity consumption of $0.4,1.2$ and 2.4 MWh/hh/year when washing cycles were set to 40,60 and $90{ }^{\circ} \mathrm{C}$, respectively. Taking into consideration that washing machines can promote water savings of approximately $36 \%$ [35], the energy increase associated with front load washing machines ranged from 0.2 to $1.5 \mathrm{MWh} / \mathrm{hh} /$ year.

The energy intensity of the modelled solar water heaters varied from 2.6 to $18.5 \mathrm{kWh} / \mathrm{m}^{3}$ (Fig. 6c), with an average of $10.8 \mathrm{kWh} / \mathrm{m}^{3}$. Aye et al. [16] estimated an energy intensity of approximately $7 \mathrm{kWh} / \mathrm{m}^{3}$ for a thermosiphon solar water heating system in Brisbane with a total collector area of $6 \mathrm{~m}^{2}$, total water consumption of $270 \mathrm{l} / \mathrm{hh} /$ day, hot water tank capacity of $270 \mathrm{l}$ and negligible heat losses in hot water tanks. The larger variation of the energy intensity in the present study is mainly due to the temporal distribution of different electricity tariffs. For instance, the energy intensity of solar systems connected to all-day, controlled and off-peak electricity tariffs was $16.0,12.3$ and $4.1 \mathrm{kWh} / \mathrm{m}^{3}$, respectively. The considerably reduced energy intensity of solar systems with night off-peak electricity back-up is related to the absence of electricity after the morning 
peak water consumption, which has promoted peak power demand in systems connected to controlled and all-day electricity supply..

Despite the optimal energy performance of solar systems connected to the night off-peak tariff, a reduction of compliance rates, with recommended minimum temperature set-point for hot water tanks equal to 30 to $45 \%$ was observed (Fig. 6d). On the other hand, the level of compliance with this parameter increased to 91 and $98 \%$ on average when controlled and all-day electricity supply were used, respectively. Solar water heating systems were able to supply water at the hot water end use temperature set-point at $98 \%$ of the time. The lowest compliance rate with for this parameter (i.e. $89 \%$ ) was observed for the solar systems with $125 \mathrm{l}$ hot water tank on night off-peak energy supply and total water consumption pattern.

Among the studied system types, solar water heating systems are likely the most resilient to Legionella outbreaks due to their larger capacity to maintain water above $60^{\circ} \mathrm{C}$; nonetheless, adequate compliance with this parameter is required in order to guarantee a safe hot water supply. If this issue is addressed successfully, the use of night off-peak electricity supply may considerably enhance the energy performance of solar system. For example, to optimise the performance of solar system with night electricity supply, solar systems with more efficient solar collectors may be utilised.

\subsection{Heat pump system}

Heat pump water heating systems had a similar electricity power peak pattern to electric systems, with power peaks occurring after hot water use or after power re-establishment in heat pump systems connected to intermittent electricity supply (Fig. 7). Nevertheless, electricity peaks associated with heat pumps were significantly lower than the ones related to electric systems due to the lower power input required to run heat pumps. 


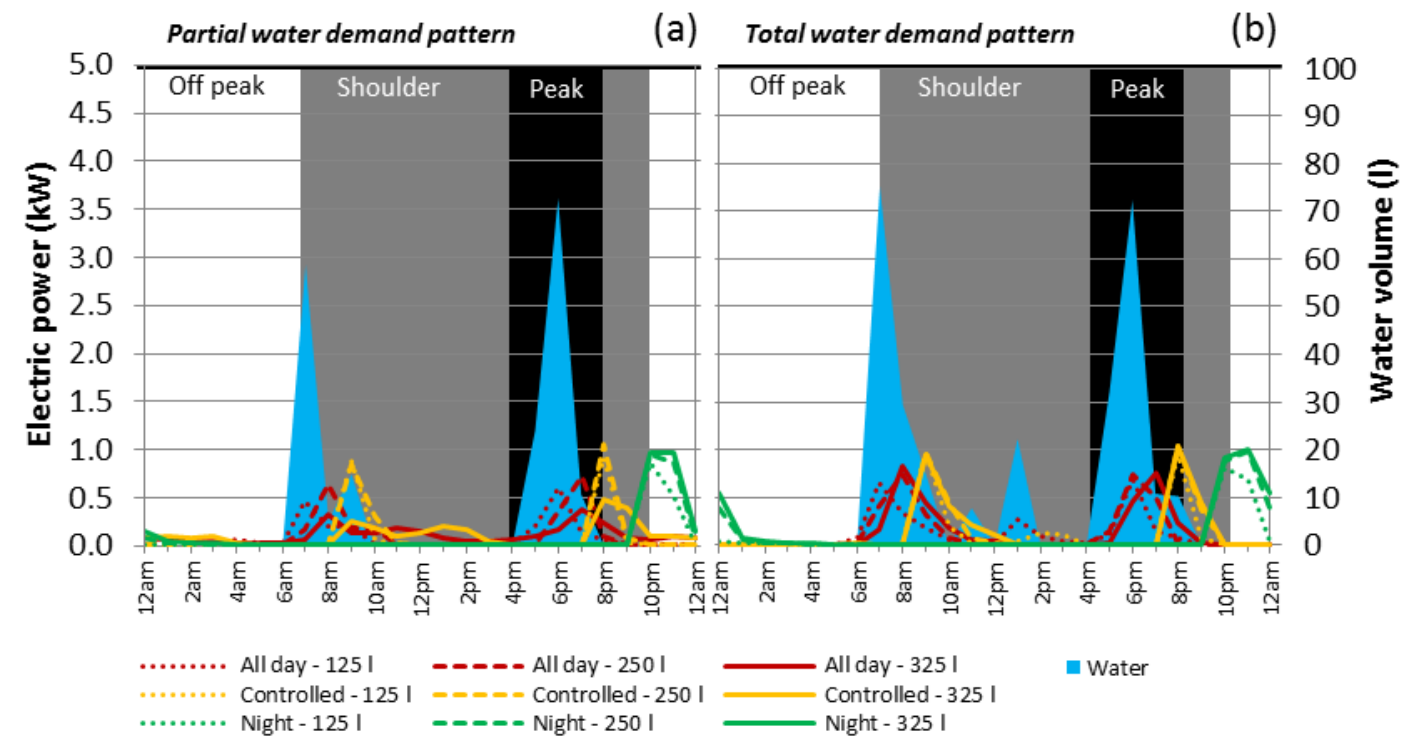

Fig. 7. Heat Pump water heater annual average water and energy demand patterns under different scenarios: tank sizes of 125, 250 and 325 l, partial and total water demand patterns, and all-day, controlled and night off-peak electricity tariffs.

When all-day electricity supply was used, the peak hour electricity consumption was approximately equal to that of electric water heaters, ranging from 27 to $43 \%$ out of the total energy consumption (Fig. 8a). The energy consumption of heat pump systems varied from 0.6 to $1.2 \mathrm{MWh} / \mathrm{hh} /$ year depending on the water consumption.

For the heap pump systems with a higher energy consumption (i.e. systems with the total water consumption and connected to all-day electricity supply), approximately $0.5 \mathrm{MWh} / \mathrm{hh} /$ year of the electricity consumption could be diverted from peak hour by using intermittent electricity supply. The increase of heat losses associated with an increase of the hot water capacity promoted a minor increase in the energy consumption of heat pumps (i.e. 0.1 $\mathrm{MWh} / \mathrm{hh} /$ year), as these systems can produce energy at a low intensity (6.5 to $14.7 \mathrm{kWh} / \mathrm{m}^{3}$ ) in comparison to electric water heaters (Fig. 8c). 

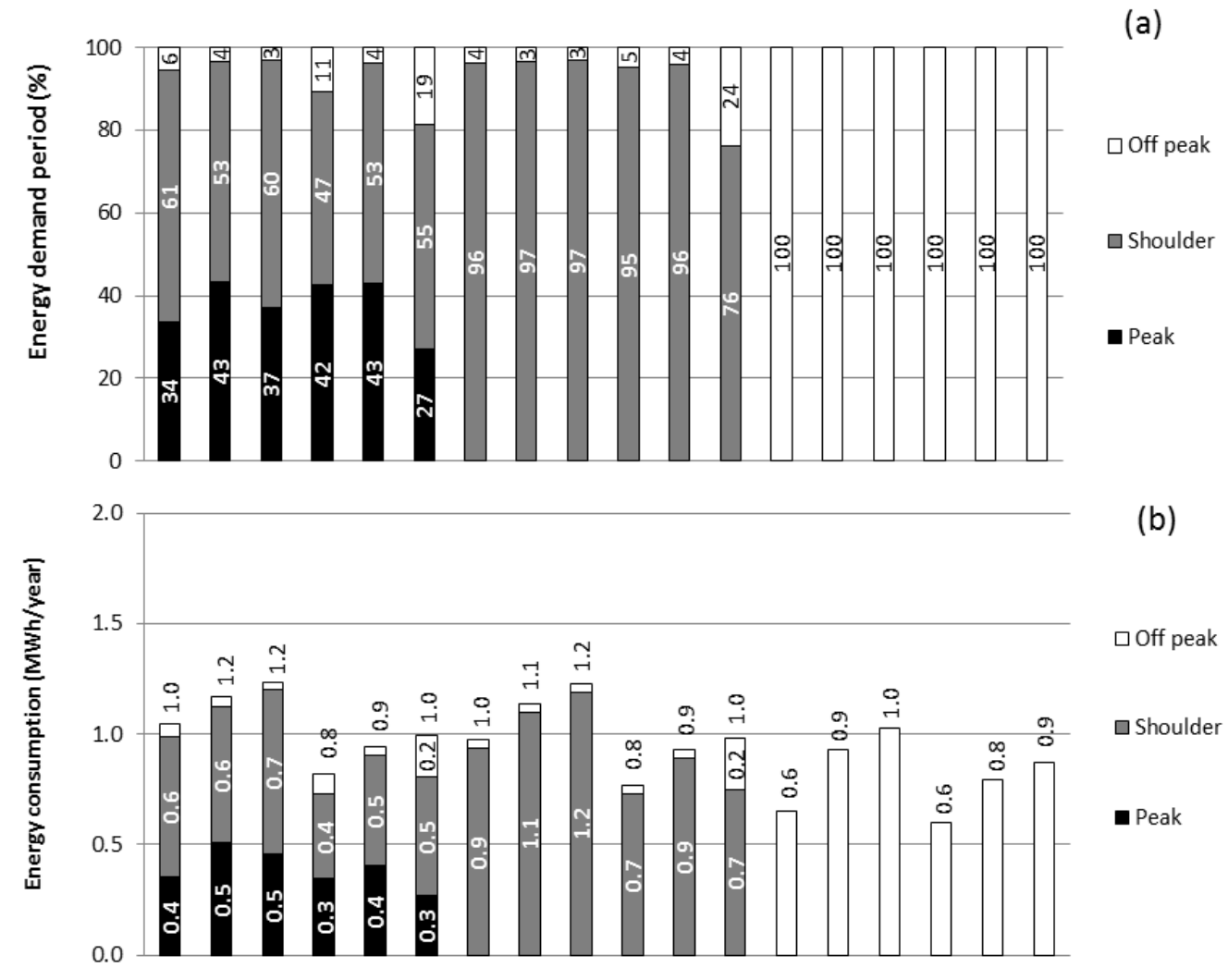

(b)

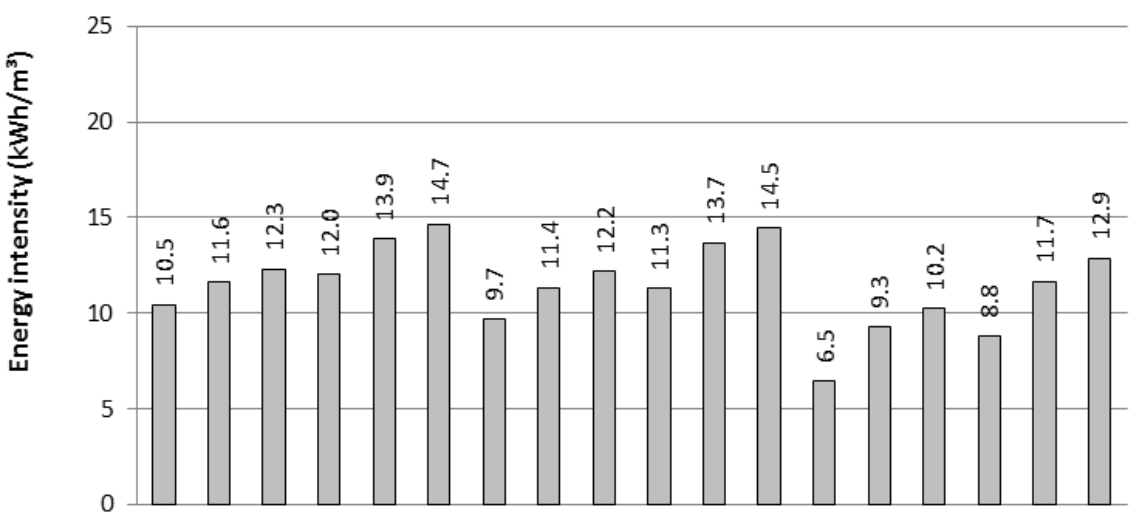

(c)

(d)

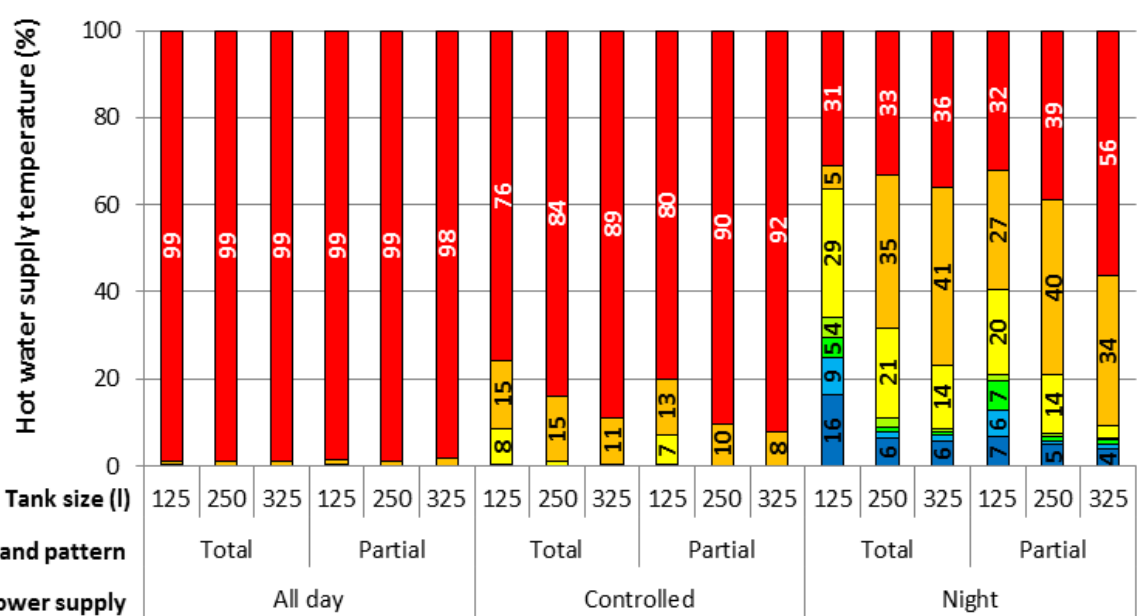

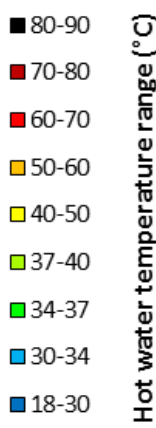

Demand pattern

Power supply

All day

Controlled 
Fig. 8. Heat Pump water heater annual average peak electricity demand (a), annual energy consumption (b), energy intensity (c) and hot water supply capacity (d) under different scenarios: tank sizes of 125, 250 and $325 \mathrm{l}$, partial and total water demand pattern, and all-day, controlled and night off-peak electricity tariffs.

In households with heat pump systems, the use of washing machines with internal heating promoted an increase in total electricity from 0.5 to $2.5 \mathrm{MWh} / \mathrm{hh} /$ year (46 to $238 \%$ ) depending on the temperature set-point during washing cycles. By taking into account a water saving potential of $36 \%$ as described by Beal and Stewart [35], this increase in electricity consumption could range from 0.2 to $1.5 \mathrm{MWh} / \mathrm{hh} /$ year (23 to $146 \%$ ).

Likewise with electric and solar water heating systems, the increase of the energy efficiency of heat pumps with the use of intermittent electricity supply resulted in a negative trade-off with the compliance rate for minimal hot water temperature set-points. Therefore, the average level of compliance with the minimal temperature set-point in hot water tanks declined from approximately $99 \%$ for heat pumps connected to all-day electricity supply to 38 and $85 \%$ by using night off-peak and controlled electricity supply, respectively (Fig. 8d). In regards to the minimal end-use temperature set-point, $100 \%$ compliance levels were achieved in systems with all-day and controlled electricity supply, and, 85 \% in systems with night off-peak. The use of larger hot water tank capacities in systems connected to intermittent energy supply promoted an increase of the compliance level with minimal hot water temperature set-points. For instance, the average compliance level with the minimal hot water temperature in tanks increased from $69 \%$ with the use of $125 \mathrm{l}$ tanks to 74 and $78 \%$ with the use of 250 and 325 l tanks, respectively.

The use of heat pumps can promote a significant reduction of the energy consumption for water heating in relation to electric water heaters. By combining this systems with controlled electricity supply, the energy consumption at peak hour for the electricity grid can be substantially reduced. Nevertheless, larger hot water tanks are necessary to maintain higher compliance ratios with minimal hot water temperature set-points in order 
to eliminate health risks associated with Legionella proliferation, as well as to guarantee high levels of comfort

to users.

\section{Water heating systems performance evaluation and comparative assessment}

The modelled scenarios, i.e. combination of different water heating systems, hot water tank sizes, electricity supply tariffs, and hot water supply end uses, were assessed against an evaluation framework with a minimum and a maximum of 0 and 10 points, respectively. In this framework, four key parameters for the performance of water heating systems clustered in two groups were taken into account, including: energy performance (i.e. percentage of electricity consumption during peak hour periods and energy intensity), and level of service (i.e. compliance with the set-point temperatures for hot water end uses and minimum temperature in hot water tanks to prevent Legionella sp. proliferation). The results obtained for the assessed scenarios were used to set benchmarks for these parameters, as shown in Table 3.

Table 3

Performance classification thresholds for domestic hot water services in Brisbane.

\begin{tabular}{lccc}
\hline \multirow{2}{*}{ Parameters } & \multicolumn{3}{c}{ Performance ranges } \\
\cline { 2 - 4 } & Poor & Intermediate & Optimal \\
\hline Electricity consumption at peak hours $(\%)$ & $\geq 5$ & $>0$ and $<5$ & 0 \\
Hot water supply energy intensity $\left(\mathrm{kWh} / \mathrm{m}^{3}\right)$ & $\geq 27$ & $>12$ and $<27$ & $\leq 12$ \\
End use temperature compliance $(\%)$ & $\leq 96$ & $>96$ and $<100$ & 100 \\
Tank lower temperature compliance $(\%)$ & $\leq 56$ & $>56$ and $<98$ & $\geq 98$ \\
\hline Equivalent score per parameter & 0 & 1.25 & 2.50 \\
\hline
\end{tabular}

All the assessed scenarios showed partial compliance of hot water services against the evaluation framework

(Table 4). The score of electric, solar and heat pump systems varied from 2.50 to $7.50,5.0$ to 7.5 , and 3.75 to 
8.75 points, respectively. Solar systems had the highest average performance (6.67 points), followed by heat

pump (6.25 points) and electric (5.28 points) systems.

\section{Table 4}

Energy performance and level of service of hot water supply services under different scenarios.

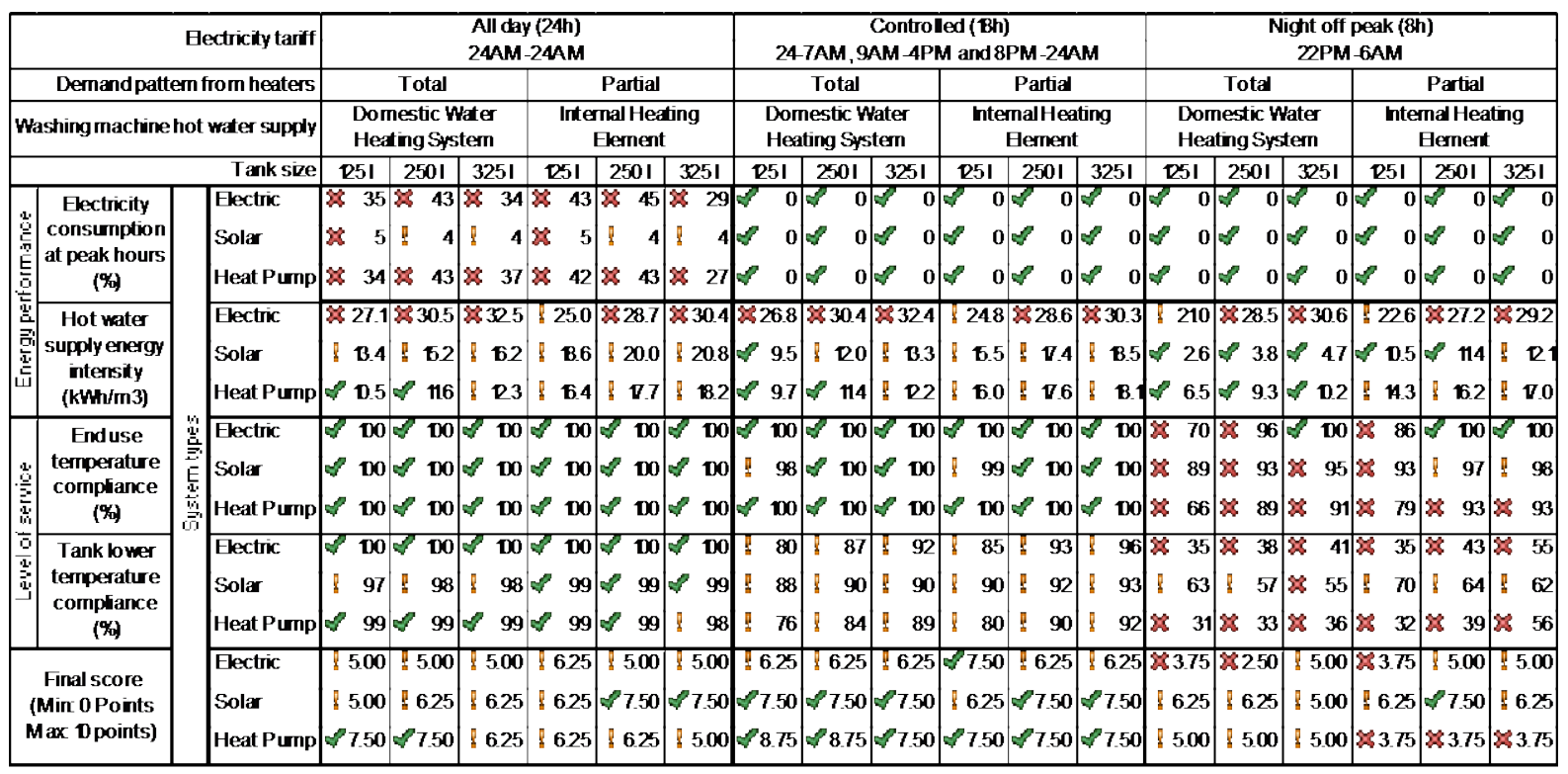

Note: Energy intensity of hot water supply services calculated considering water savings of $36 \%$ in front load washing machines with internal heating element [35].

The prevalent intermediate levels of compliance of all studied water heating technologies reveals that technology

selection alone is not sufficient to achieve high levels of performance for domestic hot water supply services. In

order to address this complex issue, attention has to be drawn to other design parameters. In the following

sub-sections, the influence of each studied parameter on the performance of hot water services is detailed.

\subsection{Electricity supply tariffs}

The time-distribution of energy according to electricity tariffs significantly influenced $(p<0.001)$ the

performance of water heating systems. On average, systems connected to a controlled electricity supply achieved 
a higher performance (7.22 points) than systems connected to all-day (6.04 points) and night off-peak supply (4.93 points).

The enhanced performance of systems under controlled electricity supply may be attributed to their capacity to divert electricity consumption from the electricity grid peak hours and maintain reasonable levels of performance with the minimal temperature threshold for hot water tanks (88\% on average). On the other hand, the lower performance of systems connected to night off-peak supply stem from the low compliance ratio with minimal temperature thresholds. For systems connected to all day supply, the intermediate performances were primarily related to the energy consumption during electricity grid peak hours.

The most efficient combination of domestic water heating technologies and electricity tariffs was observed for heat pumps and solar water heaters connected to controlled electricity tariffs, with average scores of 7.92 and 7.29 points, respectively. The poorest performance was observed for electric (4.17 points) and heap pump (4.38 points) systems connected to night off-peak electricity supply tariffs.

\subsection{Storage tank size}

The tank size was not significantly associated with a variation in the average overall performance of water heating systems $(p>0.1)$ for a $95 \%$ confidence interval. Also, the upwards trend of the energy intensity of water heating systems with an increase of the hot water tank capacity was not significant $(p>0.1)$ for a $95 \%$ confidence interval. The lack of difference was also identified by the low variability in the average overall score of systems with different storage capacities, which ranged between 5.97 and 6.18 points.

These results indicate other variables (e.g. electricity tariff) had a larger influence on the performance of domestic water heaters than the hot water tank sizes used. Note that this assumption may only be valid for the studied scenarios, taking into account a representative household in Brisbane. Therefore, hot water tank sizing 
may promote a significant variation in the performance of domestic hot water supply systems under different hot water consumption patterns and climate conditions.

\subsection{Washing machine hot water supply}

Two different hot water supply systems to washing machines were represented by the total and the partial water consumption patterns. In the first pattern (total), all hot water end uses were supplied by domestic water heaters, including the use of top load washing machines without internal heating. In the second pattern (partial), water efficient front load washing machines with internal heating elements were used, and hence were not connected to the domestic water heater. The washing machine type did not significantly influence the overall performance of domestic hot water supply $(p>0.1)$; although, the type did appear to promote a significant variation in the energy intensity of water heaters. For instance, a significant increase of approximately $4 \mathrm{kWh} / \mathrm{m}^{3}$ of the energy intensity of solar water heaters $(p<0.05)$ and heat pumps $(p<0.001)$ was observed with the used of water efficient washing machines with internal heating set to $40^{\circ} \mathrm{C}$. Such increases would be even more marked with the use of washing cycles with higher temperatures.

\section{Conclusions, recommendations and future research directions}

\subsection{Conclusions}

This article presented models of residential water heating systems for the city of Brisbane in the South East Queensland region, Australia, under different electricity supply tariffs, hot water tank capacities, and washing machine types. 
The performance of hot water services was assessed for 54 scenarios generated from the combination of three residential water heating system types (i.e. electric, solar electric boosted, and heat pump), three electricity supply tariffs (i.e. all-day (24h), controlled (18h), and night off-peak (8h)), three hot water tank capacities (i.e. 125, 250 and 325 l), and water heating systems under two water consumption patterns (i.e. partial - without connection to washing machine, and total - with connection to washing machine). Two categories of criteria were used to assess the performance of systems: (i) energy performance (i.e. electricity consumption at peak hours and energy intensity); and (ii) level of service (i.e. compliance rate with temperature set-points for hot water end uses and hot water tank).

By analysing the influence of each system configuration against the set of performance criteria, the following conclusions were drawn:

- A controlled (18h out of peak hours) electricity supply tariff has the potential to divert electricity demand away from peak hours without a considerable decrease of temperature in hot water tanks for nominal hot water tank sizes of 250 and 3251 ;

- Water heating systems connected to night off-peak electricity supply (8h) tariff for solar and heat pumps water heating systems may require tank sizes over $325 \mathrm{l}$ in order to maintain hot water within minimum set-point temperatures;

- The average estimated hot water demand of households with washing machines connected to hot water tanks is potentially higher than the one recommended in the Australian Plumbing code, and, as such, may reduce the performance of residential water heating systems on site;

- Solar systems appeared less prone to Legionella sp. outbreaks as this system type has a more stable performance due to their dual energy source (i.e. solar energy and electricity), and thus promotes a higher average temperature within hot water tanks; 
- Solar systems connected to all-day energy supply consume minimal amounts of energy during

electricity grid peak hours;

- Electric systems were shown to have a low energy performance, yet their widespread use may continue due to their low capital and maintenance costs;

- In general, the connection of washing machines to water heaters appeared to have a beneficial effect on the energy performance of domestic hot water services;

- Water efficient front load washing machines are likely to promote an increase in the energy intensity of heat pump and solar water heating systems.

\subsection{Recommendations}

The development of codes for suitable homes should address the impact of residential water heating systems in a more comprehensive way, in which not only the technology type to heat water is considered, but also the hot water demand, hot water tank size and the electricity supply tariff.

The key recommendations of the study include:

- A wider adoption of controlled electricity supply tariff as the optimal energy supply scheme to enhance the performance of water heating systems;

- Avoiding night off-peak electricity supply tariff for systems with similar characteristics to the ones studied in order to prevent extended periods of non-compliance with the minimum hot water tank temperature thresholds, and hence potentially reduce health risks associated with Legionella $s p$. proliferation;

- Increased connections of washing machines to energy efficient water heating systems with large storage capacity to enhance the energy performance of the domestic hot water supply; 
- The level of service of solar systems connected to night off-peak energy supply could be enhanced through the selection of larger solar collector areas and more efficient solar collectors;

- Where possible, water heating systems could be designed considering hot water demand patterns determined empirically in order to prevent perverse impacts from systems under sizing or oversizing;

- Increased use of domestic solar water heaters as a preferred option when using intermittent electricity supply tariffs for supplying hot water to households who are susceptible to pneumonia (e.g. elderly people), as solar systems are usually more resilient to temperature drops, and hence associated Legionella sp. growth;

- Ensuring robust hot water tanks for solar systems to allow for a high temperature range of $80-90{ }^{\circ} \mathrm{C}$ in order to enhance the collection of solar energy.

The findings and recommendations of this study apply for residential buildings in Brisbane, Australia. Likely, they may be also used as an initial baseline to infer the performance of water heating systems in other subtropical regions of the world with similar climate (e.g. South East Queensland region in Australia, coastal cities in Santa Catarina State in Brazil, etc.). Nonetheless, caution should be practiced when generalizing the herein findings, in which a case-by-case analysis is more appropriate.

\subsection{Future research directions}

Further assessment of residential water heating systems under empirical hot water demand patterns will facilitate a gradual narrowing of the knowledge gap regarding on-site energy and hot water supply performances of water heating systems. Future research directions include, but are not limited to: 
- Determination of hot water demand patterns through empirical studies taking into account household type variability across different seasonal and climatic conditions;

- Performance analysis of solar water heating systems through the installation of a variety of collector set ups under different built environments (e.g. sun exposure, roof configurations); and

- Assessment of the relationship between energy efficiency and standard of service (i.e. hot water set up temperature at water end use points).

\section{Acknowledgements}

The authors acknowledge Griffith University in Australia for providing adequate facilities and databases for the development of the present article.

\section{References}

[1] S.J. Kenway, R. Scheidegger, T. a. Larsen, P. Lant, H.-P. Bader, Water-related energy in households: A model designed to understand the current state and simulate possible measures, Energy and Buildings. 58 (2013) 378-389.

[2] L. Pérez-Lombard, J. Ortiz, C. Pout, A review on buildings energy consumption information, Energy and Buildings. 40 (2008) 394-398.

[3] T. Ramesh, R. Prakash, K.K. Shukla, Life cycle energy analysis of buildings : An overview, Energy and Buildings. 42 (2010) 1592-1600.

[4] J. Carlo, R. Lamberts, Development of envelope efficiency labels for commercial buildings: Effect of different variables on electricity consumption, Energy and Buildings. 40 (2008) 2002-2008.

[5] A. de Almeida, P. Fonseca, B. Schlomann, N. Feilberg, Characterization of the household electricity consumption in the EU, potential energy savings and specific policy recommendations, Energy and Buildings. 43 (2011) 1884-1894.

[6] K. Alanne, A. Salo, A. Saari, S.-I. Gustafsson, Multi-criteria evaluation of residential energy supply systems, Energy and Buildings. 39 (2007) 1218-1226. 
[7] R.J. Meyers, E.D. Williams, H.S. Matthews, Scoping the potential of monitoring and control technologies to reduce energy use in homes, Energy and Buildings. 42 (2010) 563-569.

[8] T. Cholewa, A. Siuta-Olcha, Experimental investigations of a decentralized system for heating and hot water generation in a residential building, Energy and Buildings. 42 (2010) 183-188.

[9] T. Cholewa, A. Siuta-Olcha, M. a. Skwarczyński, Experimental evaluation of three heating systems commonly used in the residential sector, Energy and Buildings. 43 (2011) 2140-2144.

[10] C.-L. Cheng, Study of the inter-relationship between water use and energy conservation for a building, Energy and Buildings. 34 (2002) 261-266.

[11] A. Arpke, N. Hutzler, Domestic water use in the Unitede States: a life-cycle approach, Journal of Industrial Ecology. 10 (2006) 169-184.

[12] D.J.M. Flower, An Integrated Approach to Modelling Urban Water Systems, Monash University, Melbourne, 2009.

[13] P.J. Boait, D. Dixon, D. Fan, a. Stafford, Production efficiency of hot water for domestic use, Energy and Buildings. 54 (2012) 160-168.

[14] X. Liu, S. Lau, H. Li, Optimization and analysis of a multi-functional heat pump system with air source and gray water source in heating mode, Energy \& Buildings. 69 (2014) 1-13.

[15] S. Thiers, B. Peuportier, Energy and environmental assessment of two high energy performance residential buildings, Building and Environment. 51 (2012) 276-284.

[16] L. Aye, W.W.S. Charters, C. Chaichana, Solar heat pump systems for domestic hot water, Solar Energy. 73 (2002) 169-175.

[17] S. Kenway, The water-energy nexus and urban metabolism - Connections in cities. Urban Water Security Research Alliance Technical Report 100, 2013.

[18] A. Colmenar-santos, J. Vale-vale, D. Borge-diez, R. Requena-pérez, Solar thermal systems for high rise buildings with high consumption demand : Case study for a 5 star hotel in Sao Paulo, Brazil, Energy \& Buildings. 69 (2014) 481-489.

[19] C.D. Beal, E. Bertone, R. A. Stewart, Evaluating the energy and carbon reductions resulting from resource-efficient household stock, Energy and Buildings. 55 (2012) 422-432.

[20] QLD, Delivering affordable, safe and reliable energy and water for Queensland, Queensland Government. (2012). 
[21] R. Brahme, G. Dobbs, T. Carriere, Bracketing residentail "net-zeroness” during design stage, in: Third National Conference of IBPSA-USA, July 30 - August 1, Berkeley, California, Berkeley, California, 2008: pp. 156-163.

[22] R.H. Crawford, G.J. Treloar, Net energy analysis of solar and conventional domestic hot water systems in Melbourne, Australia, Solar Energy. 76 (2004) 159-163.

[23] Z. Zhang, F. Wang, W. Da, C. Guo, Experimental Research on Performance Optimization of Solar-Air Source Heat Pump Water Heater, Advanced Materials Research. 664 (2013) 1002-1006.

[24] A. Hepbasli, Y. Kalinci, A review of heat pump water heating systems, Renewable and Sustainable Energy Reviews. 13 (2009) 1211-1229.

[25] M. Bojic, N. Nikolic, D. Nikolic, J. Skerlic, I. Miletic, Toward a positive-net-energy residential building in Serbian conditions, Applied Energy. 88 (2011) 2407-2419.

[26] J. Hong, N.J. Kelly, I. Richardson, M. Thomson, Assessing heat pumps as flexible load, Proceedings of the Institution of Mechanical Engineers, Part A: Journal of Power and Energy. 227 (2013) 30-42.

[27] R. Hendron, R. Anderson, C. Christensen, M. Eastment, P. Reeves, Development of an Energy Savings Benchmark for All Residential End-Uses, in: SIMBUILD2004 Conference, Boulder, Colorado, August 4-6, 2004, 2004: pp. 1-11.

[28] I.R. Pillai, R. Banerjee, Methodology for estimation of potential for solar water heating in a target area, Solar Energy. 81 (2007) 162-172.

[29] X. Li, W. Wu, X. Zhang, W. Shi, B. Wang, Energy saving potential of low temperature hot water system based on air source absorption heat pump, Applied Thermal Engineering. 48 (2012) 317-324.

[30] J. Darelid, S. Lofgren, B.-E. Malmvall, Control of nosocomial Legionnaires' disease by keeping the circulating hot water temperature above $55 \mathrm{C}$ : experience from a 10-year surveillance programme in a district general hospital, Journal of Hospital Infection. 50 (2002) 213-219.

[31] A. Serrano-Suárez, J. Dellundé, H. Salvadó, S. Cervero-Aragó, J. Méndez, O. Canals, et al., Microbial and physicochemical parameters associated with Legionella contamination in hot water recirculation systems., Environmental Science and Pollution Research International. 20 (2013) 5534-44.

[32] A. Bargellini, I. Marchesi, E. Righi, A. Ferrari, S. Cencetti, P. Borella, et al., Parameters predictive of Legionella contamination in hot water systems: association with trace elements and heterotrophic plate counts., Water Research. 45 (2011) 2315-21.

[33] AS/NZS 3500.4 (2003) National Plumbing and Drainage: Part 4 - Heated Water Services. Standards Australia, 2003. 
[34] Australia, Plumber Reference Guide - Solar \& Heat Pump Hot Water Systems, Department of Climate Change and Energy Efficiency - Commonwealth of Australia, 2010.

[35] C. Beal, R.A. Stewart, South East Queensland Residential End Use Study: Final Report. Urban Water Security Research Alliance Technical Report No . 47., Gold Coast, Australia, 2011.

[36] R.M. Willis, R.A. Stewart, D.P. Giurco, M.R. Talebpour, A. Mousavinejad, End use water consumption in households: impact of socio-demographic factors and efficient devices, Journal of Cleaner Production. (2011) 1-9.

[37] C.D. Beal, R.A. Stewart, Identifying residential water end-uses underpinning peak day and peak hour demand, Journal of Water Resources Planning and Management. (2013).

[38] J. Burch, P. Erickson, Using ratings data to derive simulation-model inputs for storage-tank water heaters, in: Solar 2004 Conference and 29th National Passive Solar Conference, Portland, Oregon, 2004: pp. 394-398.

[39] L. Guan, T. Berrill, R.J. Brown, Measurement of standby power for selected electrical appliances in Australia, Energy and Buildings. 43 (2011) 485-490.

[40] W. Mathys, J. Stanke, M. Harmuth, E. Junge-Mathys, Occurrence of Legionella in hot water systems of single-family residences in suburbs of two German cities with special reference to solar and district heating., International Journal of Hygiene and Environmental Health. 211 (2008) 179-85.

[41] ENERGEX, Hot Water Rewards FAQ, (2014). 


\title{
Supplementary Data
}

for

\section{Residential water heaters in Brisbane, Australia: thinking beyond technology selection to enhance energy efficiency and level of service}

\author{
Abel S. Vieira ${ }^{\mathrm{a}}$, Cara D. Beal ${ }^{\mathrm{b}}$ and Rodney A. Stewart ${ }^{\mathrm{a}}$ \\ ${ }^{a}$ School of Engineering, Griffith University, Gold Coast Campus, Queensland 4222, Australia; ${ }^{b}$ Smart Water Research Centre and School of \\ Engineering, Griffith University, Gold Coast Campus, Queensland 4222, Australia
}

APPENDIX A: Hot water consumption pattern determination

6. Summary

Representative hot water consumption patterns for households in Brisbane were obtained from the SEQ Residential End Use Study (SEQREUS) [1]. The smart metering data acquisition process and subsequent water end use classification method is described in detail by Willis et al. [2] and Beal and Stewart [3]. In the present study, it was also utilised available data associated with the SEQREUS for the hot water end uses of 12 Brisbane households in winter and summer in 2010.

7. Method use to estimate hot water consumption patterns

The average hot water consumption pattern among households was used to perform the simulations. Water end uses with similar functions, which may have interchangeable uses, were clustered together to avoid underestimating peak demands and to provide a more realistic representation of the average consumption pattern among households. Therefore, the hot water end uses were grouped as: (i) shower and bath, (ii) washing machine and (iii) taps.

The average water consumption among households for each hot water end use group was determined over a 24-hour period with hourly resolution (i.e. diurnal consumption pattern). This pattern was established considering two peak periods in order to represent the morning (am) and evening (pm) peak hours. This 
assumption was necessary to clearly define peak water consumption events that would otherwise be misrepresented if only the total average hourly consumption among households was considered. The peak hot water consumption of each end use group was calculated for weekdays and weekends during summer and winter using Eq. (A.1):

$$
P_{i}=\frac{W C_{i}}{W C_{m}} \times 100
$$

where $P_{i}$ is the percentage of the maximum daily water consumption during peak hour ' $i$ ' (\%); $W C_{i}$ is the average household (hh) water consumption (l) during the period represented by peak hour ' $\mathrm{l}$ ' (l/hh); and $W C_{m}$ is the maximum average daily household (hh) water consumption (l) on weekdays and weekends in the summer and winter $(\mathrm{l} / \mathrm{hh})$.

For the simulations, a schedule to represent the hot water consumption pattern was developed using the fraction of the maximum consumption calculated for each peak hour and the average flow rate. Two hot water consumption patterns were used to represent the studied group in the simulations: a partial consumption pattern, which was characterised by a combination of the hot water end use categories 'shower and bath' and 'taps'; and a total consumption pattern, which encompassed the end use categories 'washing machine', 'shower and baths', and 'taps'. The partial consumption pattern was used to represent households in which the washing machine was not connected to the water heating system, while the total consumption pattern represented households where the washing machine was connected to hot water from the heating system.

For the total water consumption pattern, the average water consumption of washing machines from all studied households was used as a representative consumption pattern, regardless of differences among washing machine 
types. However, top-loading washing machines usually rely on hot water from water heating systems as it has both hot and cold tap connections; while front load washing machines are typically connected to the cold water tap only and heat the water using an internal heating element (i.e. electrical resistance) [4].

The energy required to internally heat water in front load washing machines (cold tap connection only) was calculated through EnergyPlus models as an instantaneous (tankless) electric water heater.

\subsubsection{Estimated hot water consumption patterns}

The average water consumption patterns and estimated peak water demand for water end use groups with potential hot water demand are presented in Fig. A. 1-4

Fig. A. 1 presents the combined shower and bath end use category hourly water consumption patterns and the estimated fraction of the total daily water consumption during the morning and the evening peak hours for the studied households in four key periods: (a) Weekday - Winter; (b) Weekend - Winter; (c) Weekday - Summer; and (d) Weekend - Summer.

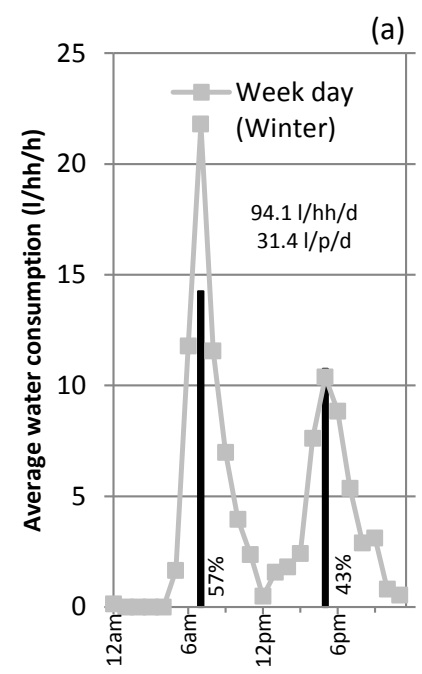

(a)

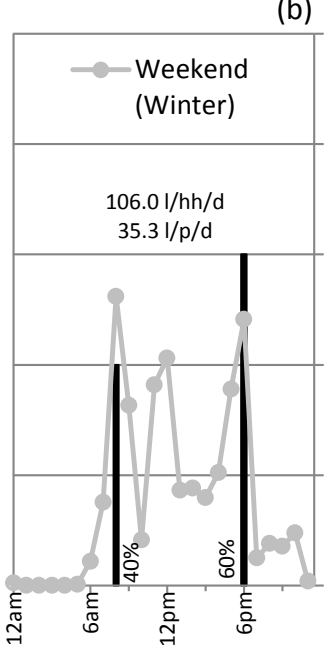

(b)

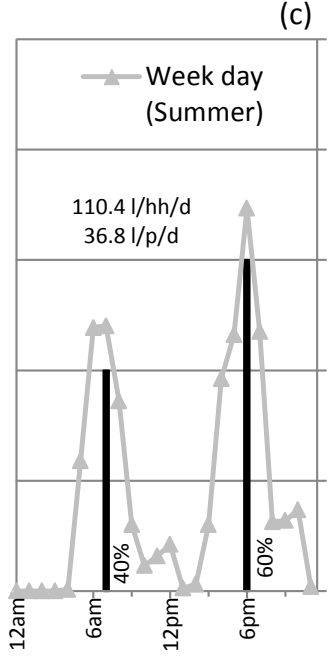

(c)
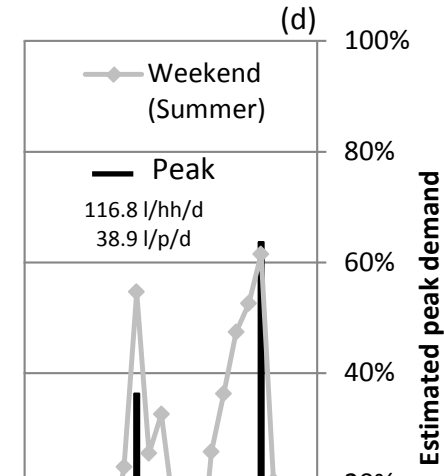
$20 \%$

Time (h)

Fig. A. 1. Shower and bath average hourly water consumption pattern (l) and estimated fraction of the total daily water demand (\%) during morning and evening peak hours (h) for the studied households (hh) during week days in winter (a), weekends in winter (b), week days in summer (c) and weekends in summer (d). 
The maximum daily water consumption pattern for the combined shower and bath end use category was observed during summer, where consumption on weekends (i.e. $116.8 \mathrm{l} / \mathrm{hh} / \mathrm{d}$ ) was slightly higher than on weekdays (i.e. 110.4 l/hh/d). During winter, the water consumption decreased to 94.1 and $106.0 \mathrm{l} / \mathrm{hh} / \mathrm{d}$ on weekdays and weekends, respectively. In both seasons, peak hour periods were generally observed during mornings and evenings. However, morning peaks were higher in winter, whereas evening peaks were higher in summer.

Despite the lower average total volume of water consumption for shower and bath on weekdays when compared to weekends, weekdays had higher peak in water consumption as householders usually have a tighter schedule for daily routines during week days (e.g. set start times to get ready for school and work in the mornings). In relation to the total daily water demand, the peak water consumption for shower and bath reached $57 \%$ at 7 am and $43 \%$ at 5 pm on weekdays in winter (Fig. A. 1a); $40 \%$ at 8 am and $60 \%$ at 6 pm on weekends in winter (Fig. A. 1b); $40 \%$ at 7 am and $60 \%$ at 6 pm on weekdays in summer (Fig. A. 1c); and $36 \%$ at 9 am and $64 \%$ at 7 pm on weekends in summer (Fig. A. 1d). 
(a)

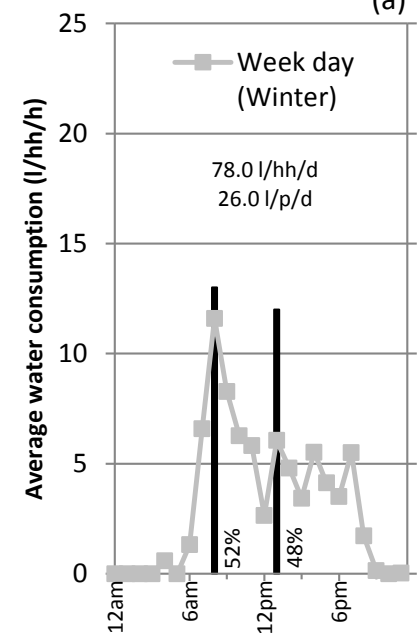

(b)

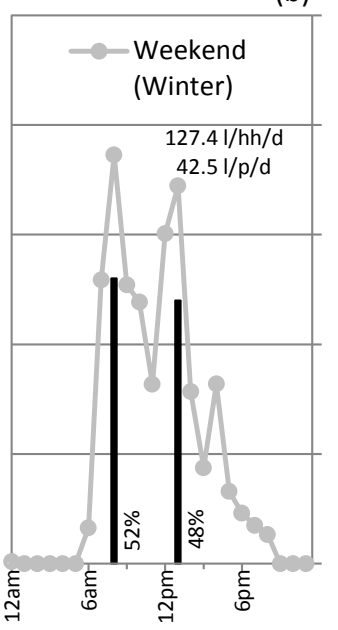

(c)

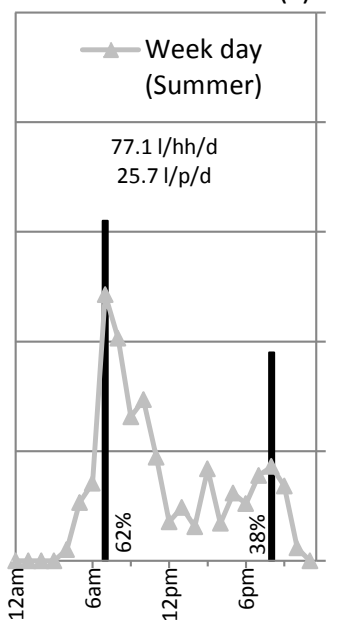

(c)
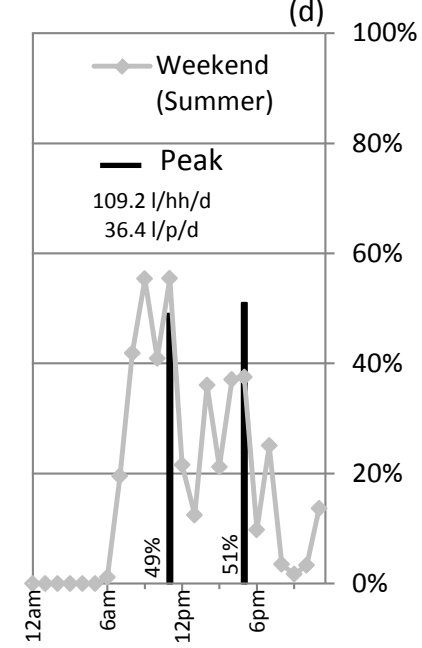

Fig. A. 2. Washing machine average hourly water consumption pattern (l) and estimated fraction of the total daily water demand (\%) during morning and evening peak hours (h) for the studied households (hh) during week days in winter (a), weekends in winter (b), week days in summer (c) and weekends in summer (d).

For washing machines, the water consumption pattern was the highest on weekends in winter (i.e. 127.4 1/hh/d) followed by weekends in summer (i.e. 109.2 l/hh/d) (Fig. A. 2). The slightly higher consumption in winter, in comparison to summer, may be due to the larger quantity of clothes washing in winter (i.e. more jackets, jeans and jumpers). On weekdays, the winter and summer patterns were similar, with water consumption of 78.0 and $77.1 \mathrm{l} / \mathrm{hh} / \mathrm{d}$, respectively. Clothes washing events are less frequent during the week since working families lack time during weekdays and cannot wait for long washing cycles to end.

Notwithstanding the more homogeneous water consumption patterns during morning periods, similar peak hour values during morning and afternoon periods were estimated in order to represent the consumption pattern of the assessed households. Morning peaks generally occurred around 8-9 am, while afternoon peaks were observed around noon in the winter and during later hours in the summer. 
(a)

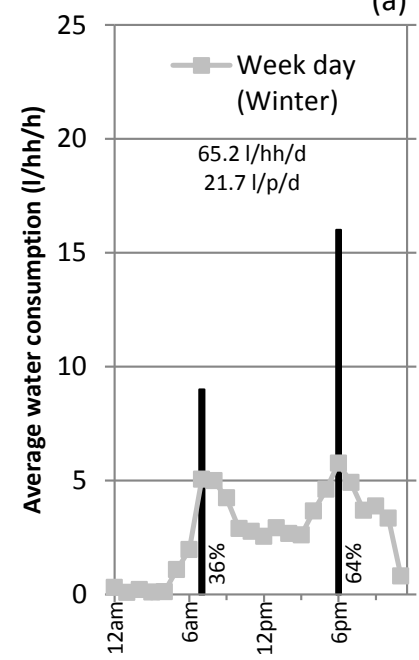

(b)

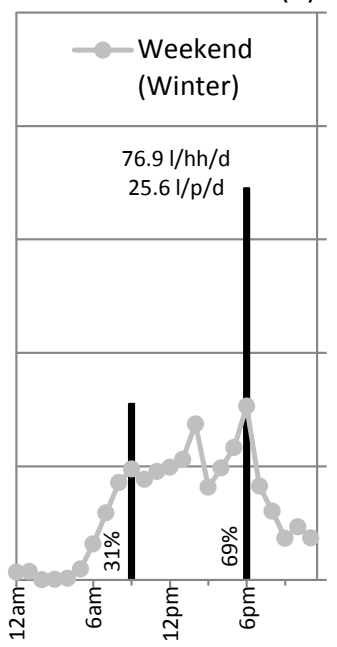

(c)

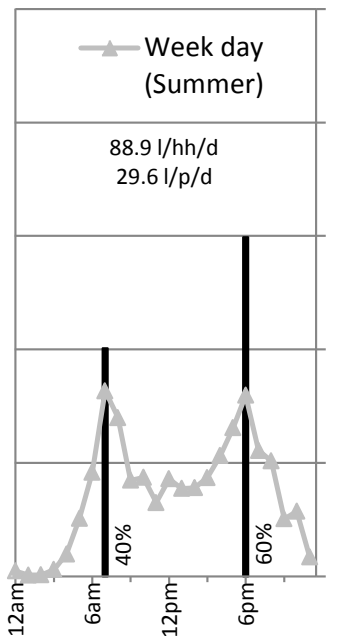

(d)

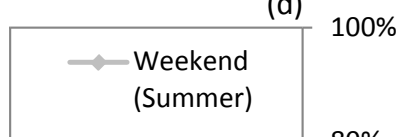

Time (h)

Fig. A. 3. Tap end use average hourly water consumption pattern (l) and estimated fraction of the total daily water demand (\%) during morning and evening peak hours (h) for the studied households (hh) during week days in winter (a), weekends in winter (b), week days in summer (c) and weekends in summer (d).

The water consumption of tap end uses was higher in summer, when the weekday and weekend patterns were equal to 88.9 and $88.0 \mathrm{l} / \mathrm{hh} / \mathrm{d}$, respectively (Fig. A. 3). On the contrary, winter consumption patterns were slightly lower on weekends (i.e. $76.9 \mathrm{l} / \mathrm{hh} / \mathrm{d}$ ) and considerably lower on weekdays (i.e. $65.2 \mathrm{l} / \mathrm{hh} / \mathrm{d}$ ).

The consumption pattern for taps was more distributed in comparison to other water end uses. Nonetheless, there was still two clear peak hour periods during the day, in which peak hours reached $36 \%$ at 7 am and $64 \%$ at 6 pm on weekdays in winter; $31 \%$ at 9 am and $69 \%$ at 6 pm on weekends in winter; $40 \%$ at 7 am and $60 \%$ at 6 pm on weekdays in summer; and $42 \%$ at 9 am and $58 \%$ at 5 pm on weekends in summer.

Two representative hot water consumption patterns were estimated for the studied households: (i) partial demand pattern (i.e. taps, and shower and bath combined); and (ii) total demand pattern (i.e. washing machine, taps, and shower and bath combined). Fig. A. 4 illustrates the estimated total demand pattern, as well as the partial demand pattern by disregarding the washing machine water consumption component represented in black. 
(a)

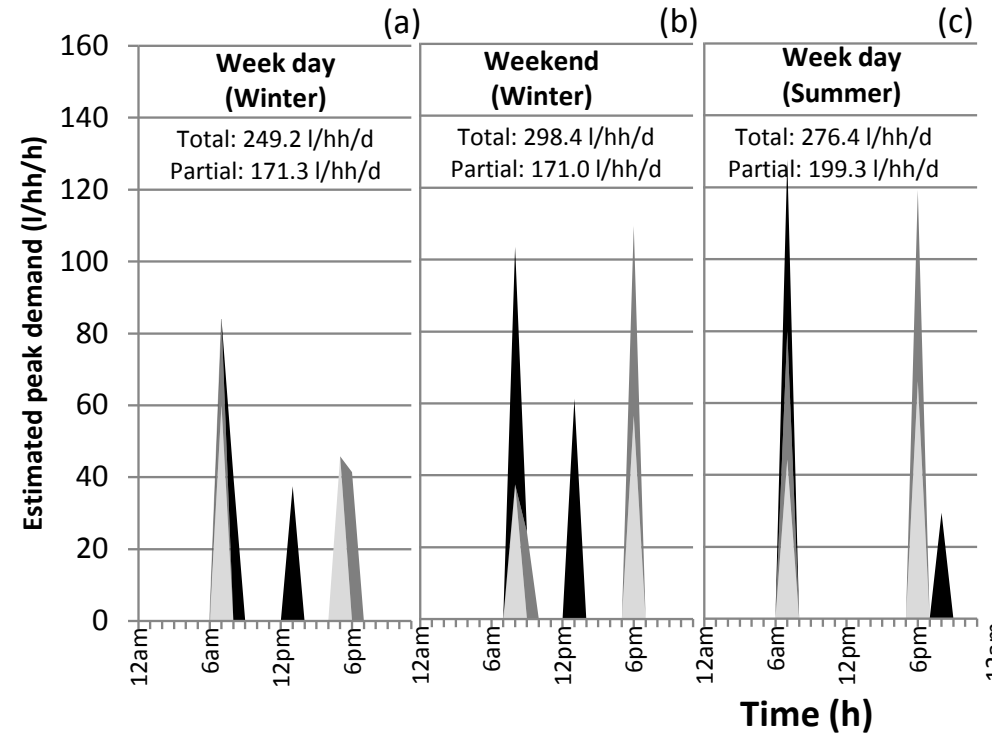

(d)

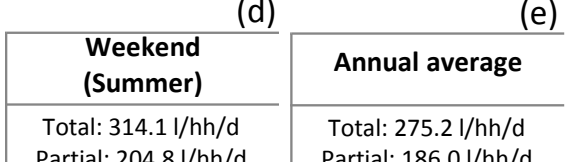

Partial: $204.8 \mathrm{l} / \mathrm{hh} / \mathrm{d} \quad$ Partial: $186.0 \mathrm{l} / \mathrm{hh} / \mathrm{d}$

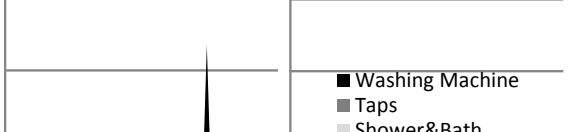

Fig. A. 4. Estimated total water demand pattern (Total: washing machine, taps, shower and bath) and estimated partial water demand pattern (Partial: taps, shower and bath).

For the partial water consumption pattern, the water demand varied from approximately $171.0 \mathrm{l} / \mathrm{hh} / \mathrm{d}$ in the winter (Fig. A. 4a and A.4b) to 199.3 and 204.8 l/hh/d on weekdays (Fig. A. 4c) and weekends (Fig. A. 4d), respectively, in the summer. The annual average water consumption for this pattern was approximately 186.0 l/hh/d (68 m³/year) (Fig. A. 4e), which is around $62 \mathrm{l} / \mathrm{p} / \mathrm{d}$, taking into account the average occupancy rate of households (i.e. three residents). This value is within the range prescribed by the Australian Plumber Reference Guide—Solar \& Heat Pump Hot Water Systems [5], which suggests an approximate hot water demand of 200 l/hh/d for households with 3-4 residents (i.e. 50 to $67 \mathrm{l} / \mathrm{p} / \mathrm{d}$ ). It is also similar to ranges described for the UK, in which Yao and Steemers [6] and Boait et al. [7] described average values of hot water consumption equal to 53 and $72 \mathrm{l} / \mathrm{p} / \mathrm{d}$, respectively.

A total water consumption pattern was estimated in order to represent households in which all hot water end uses are supplied by residential water heating systems, including hot water supply to washing machines. In such households, the estimated hot water supply from residential water heating systems increased by $48 \%$ in 
comparison to households without hot water supply to washing machines, with a consumption pattern ranging from $83 \mathrm{l} / \mathrm{p} / \mathrm{d}$ or $249 \mathrm{l} / \mathrm{hh} / \mathrm{d}$ on weekdays in winter (Fig. 6a) to $105 \mathrm{l} / \mathrm{p} / \mathrm{d}$ or $314 \mathrm{l} / \mathrm{hh} / \mathrm{d}$ on weekends in summer

(Fig. 6d). The annual average hot water demand of the total demand pattern was equal to $92 \mathrm{l} / \mathrm{p} / \mathrm{d}$ or $275 \mathrm{l} / \mathrm{hh} / \mathrm{d}$ (100 m³/year). This average is $38 \%$ higher than the hot water demand suggested by the Plumber Reference Guide for households with 3-4 residents [5]. Similar results were described by Evarts and Swan [8] in Canada, who found a higher hot water demands (67-139 l/p/d on average) for households with less than 4 residents in comparison to the hot water demand described in national standards for water heating system design (60 l/p/d).

\section{References}

[1] C. Beal, R.A. Stewart, South East Queensland Residential End Use Study: Final Report. Urban Water Security Research Alliance Technical Report No . 47., Gold Coast, Australia, 2011.

[2] R.M. Willis, R.A. Stewart, D.P. Giurco, M.R. Talebpour, A. Mousavinejad, End use water consumption in households: impact of socio-demographic factors and efficient devices, Journal of Cleaner Production. (2011) 1-9.

[3] C.D. Beal, R.A. Stewart, Identifying residential water end-uses underpinning peak day and peak hour demand, Journal of Water Resources Planning and Management. (2013).

[4] C.D. Beal, R.A. Stewart, E. Bertone, Implications of resource-efficient technology on peak water demand and water-related energy demand, in: Science Forum and Stakeholder Engagement: Building Linkages, Collaboration and Science Quality, 2012: pp. 196-204.

[5] Australia, Plumber Reference Guide - Solar \& Heat Pump Hot Water Systems, Department of Climate Change and Energy Efficiency - Commonwealth of Australia, 2010.

[6] R. Yao, K. Steemers, A method of formulating energy load profile for domestic buildings in the UK, Energy and Buildings. 37 (2005) 663-671.

[7] P.J. Boait, D. Dixon, D. Fan, a. Stafford, Production efficiency of hot water for domestic use, Energy and Buildings. 54 (2012) 160-168.

[8] J.C. Evarts, L.G. Swan, Domestic hot water consumption estimates for solar thermal system sizing, Energy and Buildings. 58 (2013) 58-65. 